\title{
Three dimensional analysis of dye-sensitized, perovskite and monocrystalline silicon solar photovoltaic cells under non uniform solar flux
}

Preeti Singh ${ }^{\mathrm{a}, 1}$, Sourav Khanna ${ }^{\mathrm{b}, 1, *}$, Vijay Mudgal ${ }^{\mathrm{c}}$, Sanjeev Newar ${ }^{\mathrm{d}}$, Vashi Sharma ${ }^{\mathrm{e}}$, Senthilarasu Sundaram ${ }^{\mathrm{f}}$, K.S. Reddy ${ }^{c}$, Tapas K. Mallick ${ }^{\mathrm{f}}$, Victor Becerra ${ }^{\mathrm{b}}$, David Hutchinson ${ }^{\mathrm{g}}$, Jovana Radulovic ${ }^{\mathrm{h}}$, Rinat Khusainov ${ }^{\mathrm{i}}$

${ }^{a}$ Simulate Learning Solutions Pvt. Ltd., Indian Institute of Technology Kanpur, Kanpur, India

${ }^{\mathrm{b}}$ School of Energy and Electronic Engineering, University of Portsmouth, Portsmouth, UK

${ }^{c}$ Department of Mechanical Engineering, Indian Institute of Technology Madras, Chennai, India

${ }^{\mathrm{d}}$ Department of Industrial and Management Engineering, Indian Institute of Technology Kanpur, Kanpur, India

${ }^{\mathrm{e}}$ Department of Mechanical Engineering, Indian Institute of Technology Kanpur, Kanpur, India

${ }^{\mathrm{f}}$ Environment and Sustainability Institute, University of Exeter, Penryn, UK

${ }^{\mathrm{g}}$ Faculty of Technology, University of Portsmouth, Portsmouth, UK

${ }^{\mathrm{h}}$ School of Mechanical and Design Engineering, University of Portsmouth, Portsmouth, UK

${ }^{i}$ School of Computing, University of Portsmouth, Portsmouth, UK

\section{Abstract}

For low/high concentration, when the distribution of solar radiation is non-uniform over the surface of the solar cell, it gets heated up non-uniformly which affects the cell efficiency. Thus, in the present work, three dimensional analysis of the solar cells is carried out under nonuniform solar flux. It involves partial differential equations. For silicon cells, studies are available that use numerical techniques (involving iterations) to solve the differential equations. However, if the differential equations can be solved analytically, one can get an analytical expression for three dimensional non-uniform temperature distribution of the cell. The current work aims at it. Dye-sensitized (DSSC), perovskite and mono-Si cells are investigated. The effects of wind direction, its speed, inclination and solar irradiance on the three dimensional temperature distribution, heat losses and cell efficiency have been investigated. It is concluded that with increase in wind azimuthal from $0^{\circ}$ to $90^{\circ}$, the efficiency decreases from $22.1 \%$ to $21.3 \%$ for mono-Si, $19.0 \%$ to $18.0 \%$ for perovskite and $12.0 \%$ to $11.9 \%$ for DSSC.

\footnotetext{
${ }^{1}$ First Authors

* Corresponding Author

Email: sourav.khanna@port.ac.uk; sourav.khanna1@gmail.com
} 


\section{Nomenclature}

$38 A_{i}$

$39 \quad B_{i}$

40

$C_{m, i}, D_{m, i} \quad$ coefficients of Eq. $31(\mathrm{~K})$

41

$E_{n, i}, F_{n, i} \quad$ coefficients of Eq. $31(\mathrm{~K})$

$42 G_{m n, i}, H_{m n, i}$

$43 \quad h$

$44 \quad H$

$45 \quad m$

$46 \quad M$

$47 \quad n$

$48 \quad N$

$49 \quad S$

$50 U$

$51 \quad \mathrm{~V}_{w}$

$52 \alpha$

$53 \beta$

$54 \quad \beta_{\mathrm{p}}$

$55 \gamma$

$56 \gamma_{w}$

$57 \varepsilon$

$58(\tau \alpha)$

coefficient of Eq. $31(\mathrm{~K})$

coefficients of Eq. $31(\mathrm{~K})$

wind speed $\left(\mathrm{ms}^{-1}\right)$

wind-azimuthal (rad)

transmittance-absorptance coefficient of Eq. $31(\mathrm{~K} / \mathrm{m})$

heat transfer coefficient due to convection $\left(\mathrm{W} / \mathrm{m}^{2} \mathrm{~K}\right)$

portion of solar irradiance leads to heat generation $\left(\mathrm{W} / \mathrm{m}^{2}\right)$

variable involved in Eq. 45

variable involved in Eq. 45

variable involved in Eq. 45

variable involved in Eq. 45

instantaneous solar-irradiance on cell $\left(\mathrm{W} / \mathrm{m}^{2}\right)$

overall coefficient for thermal loss $\left(\mathrm{W} / \mathrm{m}^{2} \mathrm{~K}\right)$

variable involved in Eq. 28

variable involved in Eq. 28

angle of inclination of the system (rad)

variable involved in Eq. 43

emissivity for long wavelength radiation 


\section{Introduction}

Advancements in solar photovoltaic proved it as an economically viable technology for electricity generation [1]. However, the cell efficiency is limited and it converts a small portion of the total irradiance into power [2]. A large portion of the irradiance leads to heat generation which affects the cell efficiency [3]. Thus, the thermal-electrical analysis of the cell needs to be carried out.

The studies that presented the one-dimensional analysis and experimental results for silicon solar cells are as follows: Goossens et al. [4] investigated the effect of wind speed on the electrical output. It was found that as wind speed decreases from $5 \mathrm{~m} / \mathrm{s}$ to $1 \mathrm{~m} / \mathrm{s}$, the electrical efficiency decreases from $18.3 \%$ to $17.7 \%$. Senturk [5] reported the effect of cloudy and partlycloudy weather on the electrical output in comparison of clear-sky weather. A reduction of $9.7 \%$ was reported in case of partly-cloudy weather and $87.6 \%$ in case of cloudy weather. Gu et al. [6] investigated the effect of inclination on the electrical output. It was reported that the change of inclination from $10^{\circ}$ to $70^{\circ}$ resulting in the drop of electrical output by $20.7 \%$ due to decrease in the incident irradiance. Ceylan et al. [7] investigated the effect of solar irradiance, wind speed and ambient temperature on the panel temperature. It was found that as solar irradiance increases from $400 \mathrm{~W} / \mathrm{m}^{2}$ to $800 \mathrm{Wm}^{-2}$, the panel temperature rises from 38.7 to $45.0^{\circ} \mathrm{C}$. Vasel and Iakovidis [8] studied the effect of wind direction on the electrical output and found that the southerly winds increase the electrical output by $24 \%$. The wind direction also affects the development of pressure field on the module [9]. Gu et al. [10] reported the electrical output for four different seasons: spring, summer, fall and winter. Ishii et al. [11] reported the temperature coefficients in order to calculate the effect of cell temperature on the electrical output. It was found that the electrical output of polycrystalline silicon cells decreases by $0.38 \%$ to $0.49 \%$ with increase in cell temperature by $1{ }^{\circ} \mathrm{C}$. Wang et al. [12] analysed the potentialinduced degraded polycrystalline silicon modules and studied the effect of the cell temperature 
on the electrical output. It was found that the electrical output decreases by $0.6051 \% / \mathrm{K}$ $0.8784 \% / \mathrm{K}$, the open circuit voltage decreases by $0.5411 \% / \mathrm{K}-0.7808 \% / \mathrm{K}$ and the short circuit current increases by $0.0900 \% / \mathrm{K}-0.1148 \% / \mathrm{K}$.

For perovskite solar cells (PSC), Zhang et al. [13] reported that the cell efficiency decreases from $16 \%$ to $9 \%$ with rise in cell temperature from $300 \mathrm{~K}$ to $360 \mathrm{~K}$. Cojocaru et al. [14] reported the decrease of efficiency from $13.5 \%$ to $6.1 \%$ with rise in cell temperature from $30^{\circ} \mathrm{C}$ to $90^{\circ} \mathrm{C}$. Zandi et al. [15] investigated the heat distribution across the layers due to light absorption, nonradiative recombination and Joule heating and a COMSOL model [16] was also built to couple the optical, electrical and thermal characteristics.

Grätzel [17] observed that raising the temperature of DSSC from $20^{\circ} \mathrm{C}$ to $60^{\circ} \mathrm{C}$ has practically no effect on the power output. Raga et al. [18] also observed a stable performance of the DSSC power output with a slight peak at $30-40^{\circ} \mathrm{C}$. On the other hand, Tripathi et al. [19] observed a significant effect of the cell temperature and solar irradiance level on the efficiency of the cell and found a decrease in the efficiency from $11 \%$ to $9.75 \%$ with an increase in cell temperature from $298 \mathrm{~K}$ to $313 \mathrm{~K}$ and increase in efficiency from $10 \%$ to $11 \%$ with an increase in irradiance level from $200 \mathrm{~W} / \mathrm{m}^{2}$ to $800 \mathrm{~W} / \mathrm{m}^{2}$. Sebastian et al. [20] also observed a decrease in efficiency from $7.7 \%$ to $6.2 \%$ with rise in cell temperature from $30^{\circ} \mathrm{C}$ to $70^{\circ} \mathrm{C}$. Pettersson et al. [21] observed a decrease in power production of $16 \%$ with rise in cell temperature from $25^{\circ} \mathrm{C}$ to $60^{\circ} \mathrm{C}$.

Studies have also been carried for two/ three dimensional analysis for silicon based cells. Chowdhury et al. [22] studied the effect of air gap underneath the module. It was found that the smaller air gap leads to lesser near-surface wind speed which can reduce the wind induced cooling and, thus, the electricity generation. Zhang et al. [23] studied the effect of nonuniformity of incident irradiance on the electrical efficiency. It was found that the electrical 
efficiency decreases by $2.1 \%$ and the fill factor decreases by $2.6 \%$. Yu et al. [24] developed two dimensional temperature-irradiance coupled model. It was found that the electrical efficiency decreases from $10.78 \%$ to $6.23 \%$ as shaded area increases from $0 \%$ to $80 \%$. Ju et al. [25] investigated the effect of irradiance distribution on the electrical output. It was found that the inverse Gaussian distribution is better than the Gaussian distribution. Zhou et al. [26] investigated the effect of back sheet on the temperature distribution. Amanlou et al. [27] investigated different geometries of diffusers to achieve uniform temperature distribution over the air cooled PV panel. It was found that the diffuser with concave side walls can achieve more uniformity. The effect of air flow rate was also analysed and found that the increase in it from 0.008 to $0.016 \mathrm{~kg} / \mathrm{s}$ improved the electrical efficiency by $13.5 \%$. Gallero et al. [28] investigated the effect of inclination angle on the temperature and velocity distributions. It was found that the system temperature decreases with increase in inclination. Pang et al. [29] investigated a ventilated photovoltaic module and compared against a closed one. It was found that an increase of $3.18 \%$ in the power output can be achieved using the ventilated one for a mass flow rate of $0.025 \mathrm{~kg} / \mathrm{s}$ and an increase of $6.06 \%$ can be achieved for $0.1 \mathrm{~kg} / \mathrm{s}$. Nouira and Sammouda [30] investigated the effect of dust deposition. It was found that a dust deposition density of $9 \mathrm{~g} / \mathrm{m}^{2}$ can reduce the PV power output by $3 \mathrm{~W}$. Khanna et al. [31] reported that the external PV cooling is more effective for low wind speed conditions as compared to high wind speed conditions. For former case, the electricity generation of PV can be increased by $10.5 \%$ and for latter case, the increment can be 5.3\% [32]. It has also been reported that the high wind speed can increase the duration of PV cooling [33].

It can be summarised that for perovskite cells and DSSC, only one-dimensional analysis had been carried out in literature considering uniform distribution of solar flux. However, for low/high concentration, the distribution of solar radiation will be non-uniform over the surface of the solar cell which had not been studied in literature yet. Under non-uniform distribution of 
$150 \quad T(x, y, z)= \begin{cases}T_{1}(x, y, z) & \text { if } 0 \leq z \leq t_{1} \\ T_{2}(x, y, z) & \text { if } t_{1} \leq z \leq t_{2} \\ T_{3}(x, y, z) & \text { if } t_{2} \leq z \leq t_{3} \\ T_{4}(x, y, z) & \text { if } t_{3} \leq z \leq t_{4} \\ T_{5}(x, y, z) & \text { if } t_{4} \leq z \leq t_{5}\end{cases}$ 


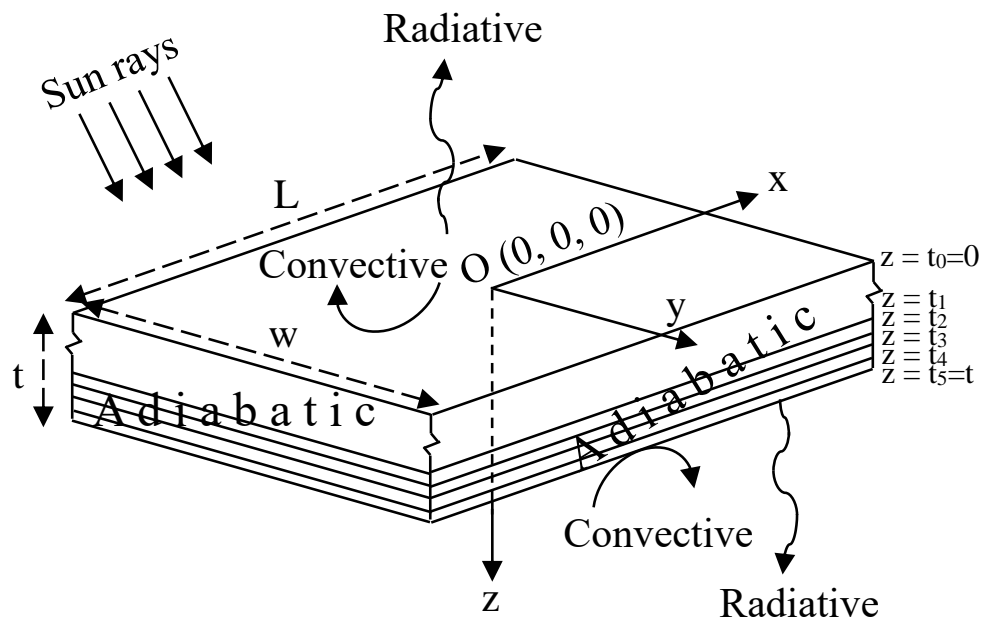

(a) Mono-Si cell 
Glass $\left(3 \times 10^{-3} \mathrm{~m}\right)$ Dye-sensitized $\mathrm{TiO}_{2}\left(12 \times 10^{-6} \mathrm{~m}\right)$ Electrolyte $\left(2 \times 10^{-6} \mathrm{~m}\right)$ Platinum $\left(300 \times 10^{-9} \mathrm{~m}\right)$ Glass $\left(3 \times 10^{-3} \mathrm{~m}\right)$

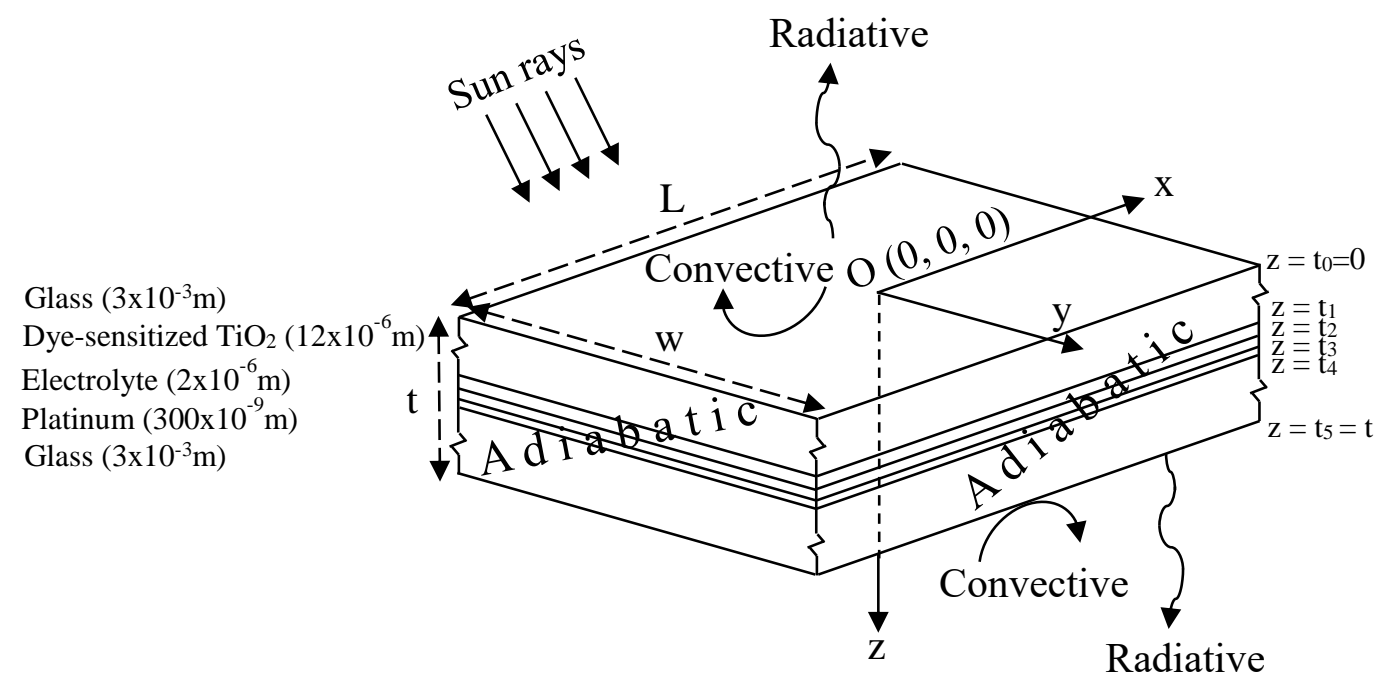

(b) Dye-sensitized cell

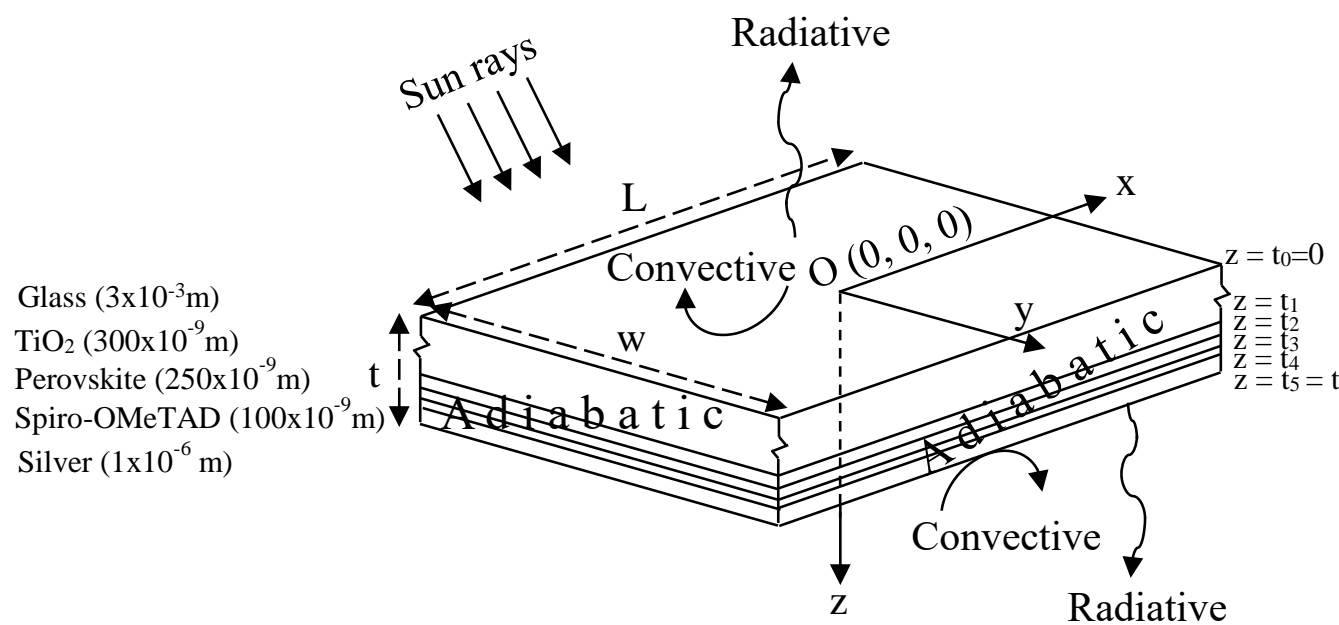

(c) Perovskite cell

The following suppositions are made while carrying out the modelling

(i) Due to negligible thickness, steady state analysis is carried out

(ii) The contact resistances are not considered

(iii) The incident solar flux follows the mirror symmetry around $x$ axis and $y$ axis

The heat generation $(H)$ can be calculated using Eq. (2) by subtracting the electricity generation from the total absorbed irradiance as follows 
165 where $\eta_{e}$ and $S$ are the electricity generation efficiency and incident solar irradiance respectively.

166 To keep the mathematical solution of the equations simpler and to fit the same analytical equation for all 167 types of cells, heat is considered to be generated at one particular surface for all types of cells. The interface 168 of second and third layer of the cell is chosen. The generated heat enters the adjacent layers. Thus, the 169 addition of the heat flowing towards upper and lower layers can be equated to the generated heat because 170 of the steady state analysis and can be given by Eq. (3).

$171 \quad\left[k_{2} \frac{\partial T_{2}}{\partial z}{ }_{\text {at } z=t_{2}}\right]+\left[-k_{3} \frac{\partial T_{3}}{\partial z_{\text {at } z=t_{2}}}\right]=H(x, y)$

172 After entering the adjacent layers, heat flows via conduction. For any $i^{\text {th }}$ layer, it can be given by Eq. (4).

$173 \quad \frac{\partial^{2} T_{i}}{\partial x^{2}}+\frac{\partial^{2} T_{i}}{\partial y^{2}}+\frac{\partial^{2} T_{i}}{\partial z^{2}}=0 \quad \forall i=1$ to 5

174 At the contact surface of the two layers, the heat going into one layer is equal to the heat going out of the 175 other layer which can be given by Eq. (5).

176

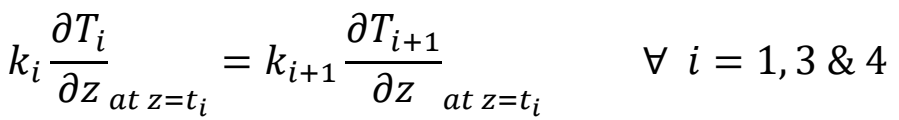

177 At the contact surface of the two layers, the temperature of one layer is equal to the temperature of the 178 other layer which can be given by Eq. (6).

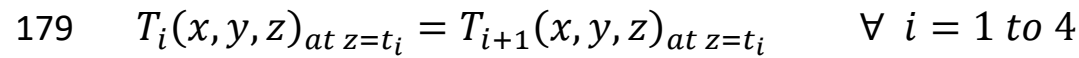

180 From the front and rear of the cells, thermal energy is lost to the environment which can be given by Eqs.

181 (7) and (8) respectively.

182

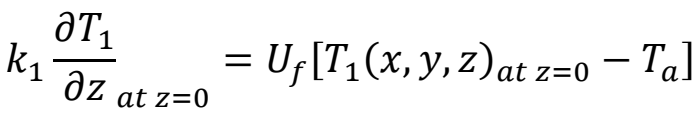


$183-k_{5} \frac{\partial T_{5}}{\partial z}{ }_{\text {at } z=t_{5}}=U_{r}\left[T_{5}(x, y, z)_{a t z=t_{5}}-T_{a}\right]$

184 where $T_{a}$ is the ambient temperature. $U_{f}$ and $U_{r}$ are the overall coefficients for the thermal loss from the 185 front and the rear of the cells respectively, which can be given by Eqs. (9) and (10).

$U_{f}\left[T_{1, a t z=0}-T_{a}\right]=h_{f}\left[T_{1, a t z=0}-T_{a}\right]+\sigma \varepsilon_{f} F_{f_{-} S}\left[T_{1, a t z=0}^{4}-T_{S}^{4}\right]+\sigma \varepsilon_{f} F_{f_{-} g}\left[T_{1, a t z=0}^{4}-T_{g}^{4}\right]$

$U_{r}\left[T_{5, a t} z=t_{5}-T_{a}\right]=h_{r}\left[T_{5, a t} z=t_{5}-T_{a}\right]+\sigma \varepsilon_{r} F_{r_{-} S}\left[T_{5, a t z=t_{5}}^{4}-T_{s}^{4}\right]+\sigma \varepsilon_{r} F_{r_{-} g}\left[T_{5, a t z=t_{5}}^{4}-T_{g}^{4}\right]$

188 The heat losses from the sides are neglected which can be given by Eqs. (11) and (12).

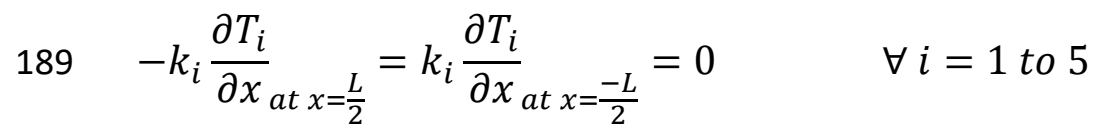

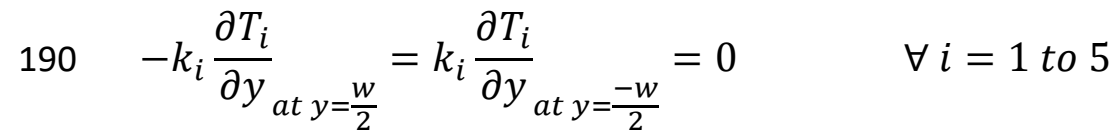

191 For most of the concentrators, the solar flux at front surface follows the mirror symmetry around $x$ axis 192 and $y$ axis. Thus, the temperature of the cell will follow the same symmetry which can be given by Eqs. 193 (13) and (14) as follows

$194 \quad T(x, y, z)=T(-x, y, z)$

$195 T(x, y, z)=T(x,-y, z)$

196 The solution of Eq. (4) can be written in the following form (Eq. 15) using separation of variables [34].

197 Thus, for $i=1$,

$198 \quad T_{1}(x, y, z)=X_{1}(x) Y_{1}(y) Z_{1}(z)$

199 Thus, for $i=1$, Eq. (4) can be written as Eq. (16).

$200 \quad Y_{1} Z_{1} \frac{\partial^{2} X_{1}}{\partial x^{2}}+X_{1} Z_{1} \frac{\partial^{2} Y_{1}}{\partial y^{2}}+X_{1} Y_{1} \frac{\partial^{2} Z_{1}}{\partial z^{2}}=0$ 
201 Dividing Eq. (16) by $X_{1} Y_{1} Z_{1}$ gives

$202 \frac{1}{X_{1}} \frac{\partial^{2} X_{1}}{\partial x^{2}}+\frac{1}{Y_{1}} \frac{\partial^{2} Y_{1}}{\partial y^{2}}+\frac{1}{Z_{1}} \frac{\partial^{2} Z_{1}}{\partial z^{2}}=0$

203 Since the boundaries are periodic in $x$ and $y$ directions, the solution follows cosine and sine functions in 204 these directions. Thus, the first and second terms of the Eq. (17) are negative because only then the 205 functions in $x$ and $y$ directions become cosine and sine. Thus, these can be given by Eqs. (18), (19) and $206(20)$

$207 \quad \frac{1}{X_{1}} \frac{\partial^{2} X_{1}}{\partial x^{2}}=-\alpha^{2}$

$208 \frac{1}{Y_{1}} \frac{\partial^{2} Y_{1}}{\partial y^{2}}=-\beta^{2}$

$209 \quad \frac{1}{Z_{1}} \frac{\partial^{2} Z_{1}}{\partial z^{2}}=\alpha^{2}+\beta^{2}$

210 The solutions of Eqs. (18-20) are given by Eqs. (21), (22) and (23).

$211 X_{1}= \begin{cases}c_{1} x+c_{2} & \text { if } \alpha=0 \\ c_{3} \cos \alpha x+c_{4} \sin \alpha x & \text { if } \alpha \neq 0\end{cases}$

$212 \quad Y_{1}= \begin{cases}c_{5} y+c_{6} & \text { if } \beta=0 \\ c_{7} \cos \beta y+c_{8} \sin \beta y & \text { if } \beta \neq 0\end{cases}$

$213 \quad Z_{1}=\left\{\begin{array}{cl}c_{9} z+c_{10} & \text { if } \alpha=\beta=0 \\ c_{11} \mathrm{e}^{-\sqrt{\alpha^{2}+\beta^{2}} z}+c_{12} \mathrm{e}^{\sqrt{\alpha^{2}+\beta^{2}} z} & \text { if }(\alpha \neq 0) \text { or }(\beta \neq 0) \text { or }(\alpha \neq 0, \beta \neq 0)\end{array}\right.$

214 Eqs. (13) and (15) give $X_{1}(x)=X_{1}(-x)$. Thus, Eq. (21) can be written as Eq. (24).

$215 X_{1}= \begin{cases}c_{2} & \text { if } \alpha=0 \\ c_{3} \cos \alpha x & \text { if } \alpha \neq 0\end{cases}$

216 Similarly, Eqs. (14) and (15) give $Y_{l}(y)=Y_{l}(-y)$. Thus, Eq. (22) can be written as Eq. (25). 
$217 \quad Y_{1}= \begin{cases}c_{6} & \text { if } \beta=0 \\ c_{7} \cos \beta y & \text { if } \beta \neq 0\end{cases}$

218 Using Eqs. (15), (23), (24) and (25), $T_{1}(x, y, z)$ can be given by Eq. (26).

$219 T_{1}(x, y, z)=\left\{\begin{array}{cl}c_{2} c_{6}\left(c_{9} z+c_{10}\right) & \text { if } \alpha=0, \beta=0 \\ \left(c_{3} \cos \alpha x\right) c_{6}\left(c_{11} \mathrm{e}^{-\alpha z}+c_{12} \mathrm{e}^{\alpha z}\right) & \text { if } \alpha \neq 0, \beta=0 \\ c_{2}\left(c_{7} \cos \beta y\right)\left(c_{11} \mathrm{e}^{-\beta z}+c_{12} \mathrm{e}^{\beta z}\right) & \text { if } \alpha=0, \beta \neq 0 \\ \left(c_{3} \cos \alpha x\right)\left(c_{7} \cos \beta y\right)\left(c_{11} \mathrm{e}^{-\sqrt{\alpha^{2}+\beta^{2} z}}+c_{12} \mathrm{e}^{\sqrt{\alpha^{2}+\beta^{2}} z}\right) & \text { if } \alpha \neq 0, \beta \neq 0\end{array}\right.$

220 Thus, by combining the constants, Eq. (26) can be written as Eq. (27).

$221 T_{1}(x, y, z)=\left\{\begin{array}{cc}A_{1} z+B_{1} & \text { if } \alpha=0, \beta=0 \\ \cos \alpha x\left(C_{1} \mathrm{e}^{-\alpha z}+D_{1} \mathrm{e}^{\alpha z}\right) & \text { if } \alpha \neq 0, \beta=0 \\ \cos \beta y\left(E_{1} \mathrm{e}^{-\beta z}+F_{1} \mathrm{e}^{\beta z}\right) & \text { if } \alpha=0, \beta \neq 0 \\ \cos \alpha x \cos \beta y\left(G_{1} \mathrm{e}^{-\sqrt{\alpha^{2}+\beta^{2}} z}+H_{1} \mathrm{e}^{\sqrt{\alpha^{2}+\beta^{2}} z}\right) & \text { if } \alpha \neq 0, \beta \neq 0\end{array}\right.$

222 Eqs. (11) \& (27) give $\sin (\alpha \mathrm{L} / 2)=0$ and Eqs. (12) \& (27) give $\sin (\beta \mathrm{w} / 2)=0$. Thus,

$223 \alpha=\frac{2 m \pi}{L} \& \beta=\frac{2 n \pi}{w} \quad$ where $m \& n$ are integers

224 Thus, Eq. (27) can be written as Eq. (29).

$225 T_{1}= \begin{cases}A_{1} z+B_{1} & \text { if } m=0, n=0 \\ \cos \frac{2 m \pi x}{L}\left(C_{1} \mathrm{e}^{-\frac{2 m \pi z}{L}}+D_{1} \mathrm{e}^{\frac{2 m \pi z}{L}}\right) & \text { if } m \neq 0, n=0, m \text { is integer } \\ \cos \frac{2 n \pi y}{w}\left(E_{1} \mathrm{e}^{-\frac{2 n \pi z}{w}}+F_{1} \mathrm{e}^{\frac{2 n \pi z}{w}}\right) & \text { if } m=0, n \neq 0, n \text { is integer } \\ \cos \frac{2 m \pi x}{L} \cos \frac{2 n \pi y}{w}\left(G_{1} \mathrm{e}^{-\sqrt{\alpha^{2}+\beta^{2}} z}+H_{1} \mathrm{e}^{\sqrt{\alpha^{2}+\beta^{2}} z}\right) & \text { if } m \neq 0, n \neq 0, m, n \text { are integers }\end{cases}$

226 Thus, for $i=1$, the complete solution of Eq. (4) can be written as Eq. (30). 
$227 \quad T_{1}(x, y, z)=A_{1} z+B_{1}+\sum_{m=1}^{\infty}\left[\cos \frac{2 m \pi x}{L}\left(C_{m, 1} \mathrm{e}^{-\frac{2 m \pi z}{L}}+D_{m, 1} \mathrm{e}^{\frac{2 m \pi z}{L}}\right)\right]$

$$
\begin{aligned}
& +\sum_{n=1}^{\infty}\left[\cos \frac{2 n \pi y}{w}\left(E_{n, 1} \mathrm{e}^{-\frac{2 n \pi z}{w}}+F_{n, 1} \mathrm{e}^{\frac{2 n \pi z}{w}}\right)\right] \\
& +\sum_{m=1}^{\infty} \sum_{n=1}^{\infty}\left[\cos \frac{2 m \pi x}{L} \cos \frac{2 n \pi y}{w}\left(G_{m n, 1} \mathrm{e}^{-\sqrt{\frac{m^{2}}{L^{2}}+\frac{n^{2}}{w^{2}}} 2 \pi z}+H_{m n, 1} \mathrm{e}^{\sqrt{\frac{m^{2}}{L^{2}}+\frac{n^{2}}{w^{2}}} 2 \pi z}\right)\right]
\end{aligned}
$$

230 Similarly, for each $i^{\text {th }}$ layer, the solution of Eq. (4) can be written as Eq. (31).

231

$$
T_{i}(x, y, z)=A_{i} z+B_{i}+\sum_{m=1}^{\infty}\left[\cos \frac{2 m \pi x}{L}\left(C_{m, i} \mathrm{e}^{-\frac{2 m \pi z}{L}}+D_{m, i} \mathrm{e}^{\frac{2 m \pi z}{L}}\right)\right]
$$

$$
\begin{aligned}
& +\sum_{n=1}^{\infty}\left[\cos \frac{2 n \pi y}{w}\left(E_{n, i} \mathrm{e}^{-\frac{2 n \pi z}{w}}+F_{n, i} \mathrm{e}^{\frac{2 n \pi z}{w}}\right)\right] \\
& +\sum_{m=1}^{\infty} \sum_{n=1}^{\infty}\left[\cos \frac{2 m \pi x}{L} \cos \frac{2 n \pi y}{w}\left(G_{m n, i} \mathrm{e}^{-\sqrt{\frac{m^{2}}{L^{2}}+\frac{n^{2}}{w^{2}}} 2 \pi z}+H_{m n, i} \mathrm{e}^{\sqrt{\frac{m^{2}}{L^{2}}+\frac{n^{2}}{w^{2}}} 2 \pi z}\right)\right]
\end{aligned}
$$

234 The constants $A_{i}, B_{i}, C_{m, i}, D_{m, i}, E_{n, i}, F_{n, i}, G_{m n, i}$ and $H_{m n . i}$ can be found out by using the following procedure. 235 Integration of the Eqs. (3), (5), (6), (7) and (8) from $x=-\mathrm{L} / 2$ to $\mathrm{L} / 2$ and from $\mathrm{y}=-\mathrm{w} / 2$ to w/2 gives Eqs. 236 (A.1)-(A.10). By solving these ten Eqs. and using the fact that $\int_{-L / 2}^{L / 2} \cos \frac{2 m \pi x}{L} d x=0$ and $237 \int_{-w / 2}^{w / 2} \cos \frac{2 n \pi y}{w} d y=0$, the expressions for $A_{i}$ and $B_{i}$ are obtained which are given in Eqs. (32)-(38) as 238 follows

$$
A_{1}=\frac{\frac{1}{L w} \int_{-L / 2}^{L / 2} \int_{-w / 2}^{w / 2} H(x, y) d x d y\left[-\frac{t_{2}}{k_{3}}+\left(\frac{1}{k_{3}}-\frac{1}{k_{4}}\right) t_{3}+\left(\frac{1}{k_{4}}-\frac{1}{k_{5}}\right) t_{4}+\frac{t_{5}}{k_{5}}+\frac{1}{U_{r}}\right]}{k_{1}\left[\left(\frac{1}{k_{1}}-\frac{1}{k_{2}}\right) t_{1}+\left(\frac{1}{k_{2}}-\frac{1}{k_{3}}\right) t_{2}+\left(\frac{1}{k_{3}}-\frac{1}{k_{4}}\right) t_{3}+\left(\frac{1}{k_{4}}-\frac{1}{k_{5}}\right) t_{4}+\frac{1}{k_{5}} t_{5}+\frac{1}{U_{f}}+\frac{1}{U_{r}}\right]}
$$

$240 \quad A_{2}=\frac{k_{1}}{k_{2}} A_{1}$ 
$241 \quad A_{3}=\frac{1}{k_{3}}\left[k_{1} A_{1}-\frac{1}{L w} \int_{-L / 2}^{L / 2} \int_{-w / 2}^{w / 2} H(x, y) d x d y\right]$

$242 \quad A_{4}=\frac{1}{k_{4}}\left[k_{1} A_{1}-\frac{1}{L w} \int_{-L / 2}^{L / 2} \int_{-w / 2}^{w / 2} H(x, y) d x d y\right]$

$243 \quad A_{5}=\frac{1}{k_{5}}\left[k_{1} A_{1}-\frac{1}{L w} \int_{-L / 2}^{L / 2} \int_{-w / 2}^{w / 2} H(x, y) d x d y\right]$

$244 \quad B_{1}=\frac{k_{1} A_{1}+U_{t} T_{a}}{U_{t}}$

$245 \quad B_{i}=B_{i-1}+\left(A_{i-1}-A_{i}\right) t_{i-1} \quad$ for $i=2$ to 5

246 By multiplying the Eqs. (3), (5), (6), (7) and (8) with $\cos \frac{2 m \pi x}{L}$ and integrating from $\mathrm{x}=-\mathrm{L} / 2$ to $\mathrm{L} / 2$ and 247 from $y=-w / 2$ to w/2, Eqs. (B.1)-(B.10) are obtained. By solving these ten Eqs. and using the fact that $248 \quad \int_{-L / 2}^{L / 2} \cos \frac{2 m \pi x}{L} d x=0$ and $\int_{-L / 2}^{L / 2}\left[\cos \frac{2 m \pi x}{L}\right]^{2} d x=\frac{L}{2}$, the expressions for $C_{m, i}$ and $D_{m, i}$ (for $i=1$ to 5) are 249 derived which are given in Eq. (39) as follows

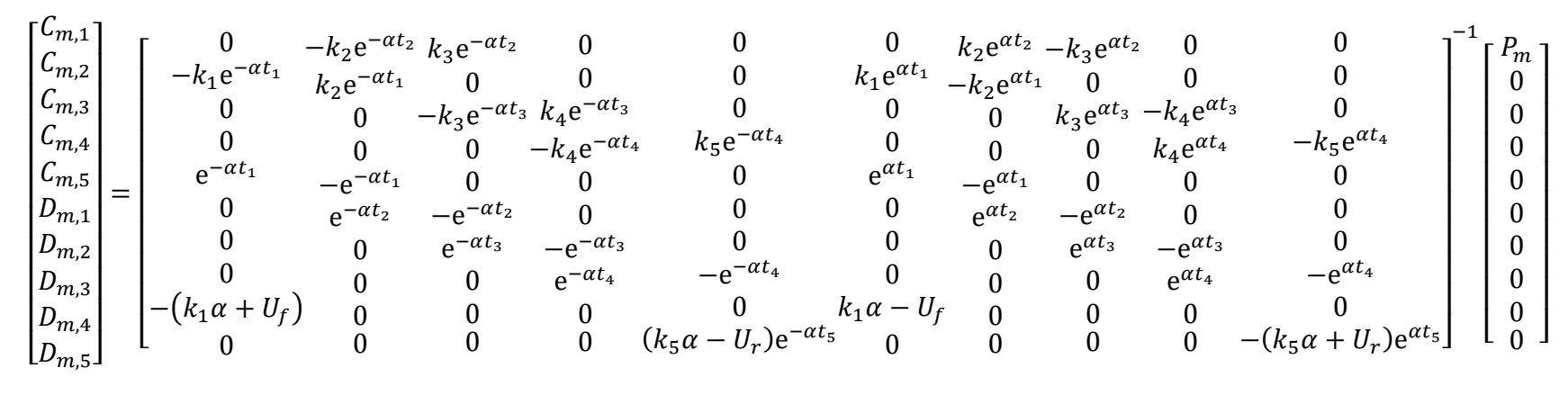

252 where, $\alpha$ and $\mathrm{P}_{\mathrm{m}}$ are given by Eqs. (28) and (40)

$$
P_{m}=\frac{2}{\alpha L w} \int_{-L / 2}^{L / 2} \int_{-w / 2}^{w / 2} H(x, y) \cos \frac{2 m \pi x}{L} d x d y
$$


254 Similarly, by multiplying the Eqs. (3), (5), (6), (7) and (8) with $\cos \frac{2 n \pi y}{L}$ and integrating from $\mathrm{x}=-\mathrm{L} / 2$ to $255 \mathrm{~L} / 2$ and from $\mathrm{y}=-\mathrm{w} / 2$ to $\mathrm{w} / 2$, the expressions for $E_{m, i}$ and $F_{m, i}$ (for $i=1$ to 5) are derived which are given 256 in Eq. (41) as follows

257

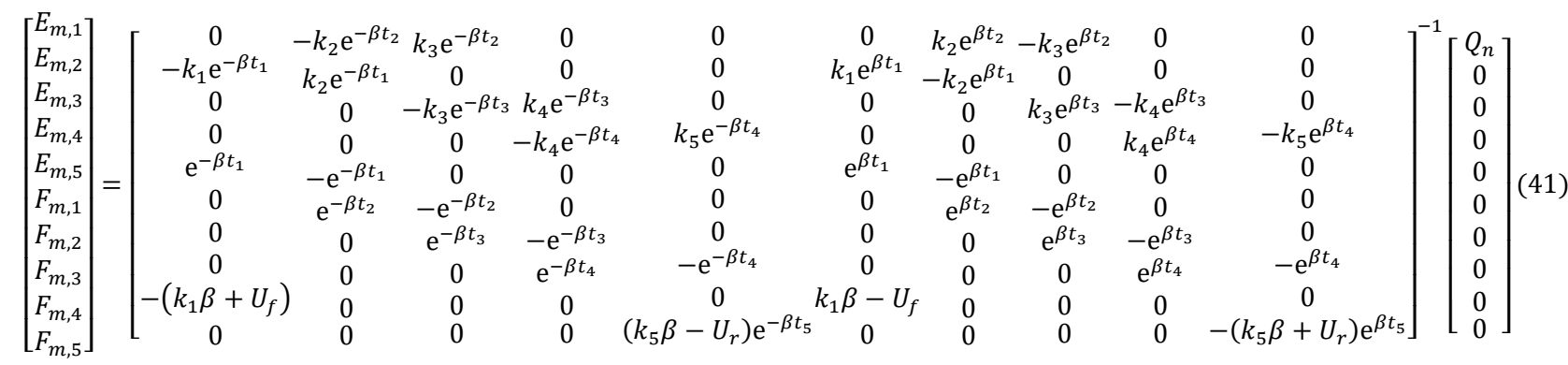

258 where, $\beta$ and $\mathrm{Q}_{\mathrm{n}}$ are given by Eqs. (28) and (42)

259

$Q_{n}=\frac{2}{\beta L w} \int_{-L / 2}^{L / 2} \int_{-w / 2}^{w / 2} H(x, y) \cos \frac{2 n \pi y}{L} d x d y$

260 Similarly, by multiplying the Eqs. (3), (5), (6), (7) and (8) with $\cos \frac{2 m \pi x}{L}$ and $\cos \frac{2 n \pi y}{w}$ and integrating from $261 \mathrm{x}=-\mathrm{L} / 2$ to $\mathrm{L} / 2$ and from $\mathrm{y}=-\mathrm{w} / 2$ to $\mathrm{w} / 2$, the expressions for $G_{m n, i}$ and $H_{m n, i}$ (for $i=1$ to 5 ) are derived 262 which are given in Eq. (43) as follows

$$
\left[\begin{array}{c}
G_{m n, 1} \\
G_{m n, 2} \\
G_{m n, 3} \\
G_{m n, 4} \\
G_{m n, 5} \\
H_{m n, 1} \\
H_{m n, 2} \\
H_{m n, 3} \\
H_{m n, 4} \\
H_{m n, 5}
\end{array}\right]=\left[\begin{array}{cccccccccc}
0 & -k_{2} \mathrm{e}^{-\gamma t_{2}} & k_{3} \mathrm{e}^{-\gamma t_{2}} & 0 & 0 & 0 & k_{2} \mathrm{e}^{\gamma t_{2}}-k_{3} \mathrm{\gamma}^{2 t_{2}} & 0 & 0 \\
-k_{1} \mathrm{e}^{-\gamma t_{1}} & k_{2} \mathrm{e}^{-\gamma t_{1}} & 0 & 0 & 0 & k_{1} \mathrm{e}^{\gamma t_{1}} & -k_{2} \mathrm{e}^{\gamma t_{1}} & 0 & 0 & 0 \\
0 & 0 & -k_{3} \mathrm{e}^{-\gamma t_{3}} & k_{4} \mathrm{e}^{-\gamma t_{3}} & 0 & 0 & 0 & k_{3} \mathrm{e}^{\gamma t_{3}}-k_{4} \mathrm{e}^{\gamma t_{3}} & 0 \\
0 & 0 & 0 & -k_{4} \mathrm{e}^{-\gamma t_{4}} & k_{5} \mathrm{e}^{-\gamma t_{4}} & 0 & 0 & 0 & k_{4} \mathrm{e}^{\gamma t_{4}} & -k_{5} \mathrm{e}^{\gamma t_{4}} \\
\mathrm{e}^{-\gamma t_{1}} & -\mathrm{e}^{-\gamma t_{1}} & 0 & 0 & 0 & \mathrm{e}^{\gamma t_{1}} & -\mathrm{e}^{\gamma t_{1}} & 0 & 0 & 0 \\
0 & \mathrm{e}^{-\gamma t_{2}} & -\mathrm{e}^{-\gamma t_{2}} & 0 & 0 & 0 & \mathrm{e}^{\gamma t_{2}} & -\mathrm{-}^{\gamma t_{2}} & 0 & 0 \\
0 & 0 & \mathrm{e}^{-\gamma t_{3}} & -\mathrm{e}^{-\gamma t_{3}} & 0 & 0 & 0 & \mathrm{e}^{\gamma t_{3}} & -\mathrm{e}^{\gamma t_{3}} & 0 \\
0 & 0 & 0 & \mathrm{e}^{-\gamma t_{4}} & -\mathrm{e}^{-\gamma t_{4}} & 0 & 0 & 0 & \mathrm{e}^{\gamma t_{4}} & -\mathrm{e}^{\gamma t_{4}} \\
-\left(k_{1} \gamma+U_{f}\right) & 0 & 0 & 0 & 0 & k_{1} \gamma-U_{f} & 0 & 0 & 0 & 0 \\
0 & 0 & 0 & 0 & \left(k_{5} \gamma-U_{r}\right) \mathrm{e}^{-\gamma t_{5}} & 0 & 0 & 0 & 0 & -\left(k_{5} \gamma+U_{r}\right) \mathrm{e}^{\gamma t_{5}}
\end{array}\right]^{-1}\left[\begin{array}{c}
R_{m n} \\
0 \\
0 \\
0 \\
0 \\
0 \\
0 \\
0 \\
0 \\
0
\end{array}\right]
$$

265 where, $\gamma=\sqrt{\alpha^{2}+\beta^{2}}$ and $\alpha, \beta$ are given by Eq. (28) and $R_{m n}$ is given by Eq. (44)

$$
R_{m n}=\frac{4}{\gamma L w} \int_{-L / 2}^{L / 2} \int_{-w / 2}^{w / 2} H(x, y) \cos \frac{2 m \pi x}{L} \cos \frac{2 n \pi y}{L} d x d y
$$


267 It is also found that, as $\mathrm{m}$ and $\mathrm{n}$ increase, the magnitudes of the terms inside the 'summation bracket' in 268 Eq. (31) decrease. Thus, there is no need to sum up the terms to $\infty$ and there exists very small finite integers $269 \mathrm{M}$ and $\mathrm{N}$ such that, for $\mathrm{m}>\mathrm{M}$ and $\mathrm{n}>\mathrm{N}$, the terms inside the 'summation bracket' are negligible. Thus, Eq. 270 (31) can be written as Eq. (45).

$T_{i}(x, y, z)=A_{i} z+B_{i}+\sum_{m=1}^{M}\left[\cos \frac{2 m \pi x}{L}\left(C_{m, i} \mathrm{e}^{-\frac{2 m \pi z}{L}}+D_{m, i} \mathrm{e}^{\frac{2 m \pi z}{L}}\right)\right]$

$$
\begin{aligned}
& +\sum_{n=1}^{N}\left[\cos \frac{2 n \pi y}{w}\left(E_{n, i} \mathrm{e}^{-\frac{2 n \pi z}{w}}+F_{n, i} \mathrm{e}^{\frac{2 n \pi z}{w}}\right)\right] \\
& +\sum_{m=1}^{M} \sum_{n=1}^{N}\left[\cos \frac{2 m \pi x}{L} \cos \frac{2 n \pi y}{w}\left(G_{m n, i} \mathrm{e}^{-\sqrt{\frac{m^{2}}{L^{2}}+\frac{n^{2}}{w^{2}}} 2 \pi z}+H_{m n, i} \mathrm{e}^{\sqrt{\frac{m^{2}}{L^{2}}+\frac{n^{2}}{w^{2}}} 2 \pi z}\right)\right]
\end{aligned}
$$

274 The above equation is the general solution of Eq. (4). $A_{i}, B_{i}, C_{m, i}, D_{m, i}, E_{n, i}, F_{n, i}, G_{m n, i}$ and $H_{m n . i}$ are given 275 in Eqs. (32)-(39), (41) and (43).

\section{3. Validation}

277 A numerical technique (using iterations) has been presented by Bonacina and Comini [35] for calculating the three dimensional temperature distribution. For validation purpose, the results are computed using the methodology of the current work and compared with their methodology. The parameters used are $\beta_{p}=$ $45^{\circ}, \gamma_{\mathrm{w}}=0^{\circ}, T_{a}=30^{\circ} \mathrm{C}$ and $\mathrm{v}_{\mathrm{w}}=1 \mathrm{~m} / \mathrm{s}$ and the distribution of solar radiation over the top surface of the silicon cell considered for the calculations is plotted in Fig. 2. The temperature distribution over the surface of the cell calculated using the proposed methodology is plotted in Fig. 3 along with that of Bonacina and Comini [35]. The results show that the values computed using the analytical expression (Eq. 45) differ from those of Bonacina and Comini [35] by less than $1.2^{\circ} \mathrm{C}$. 


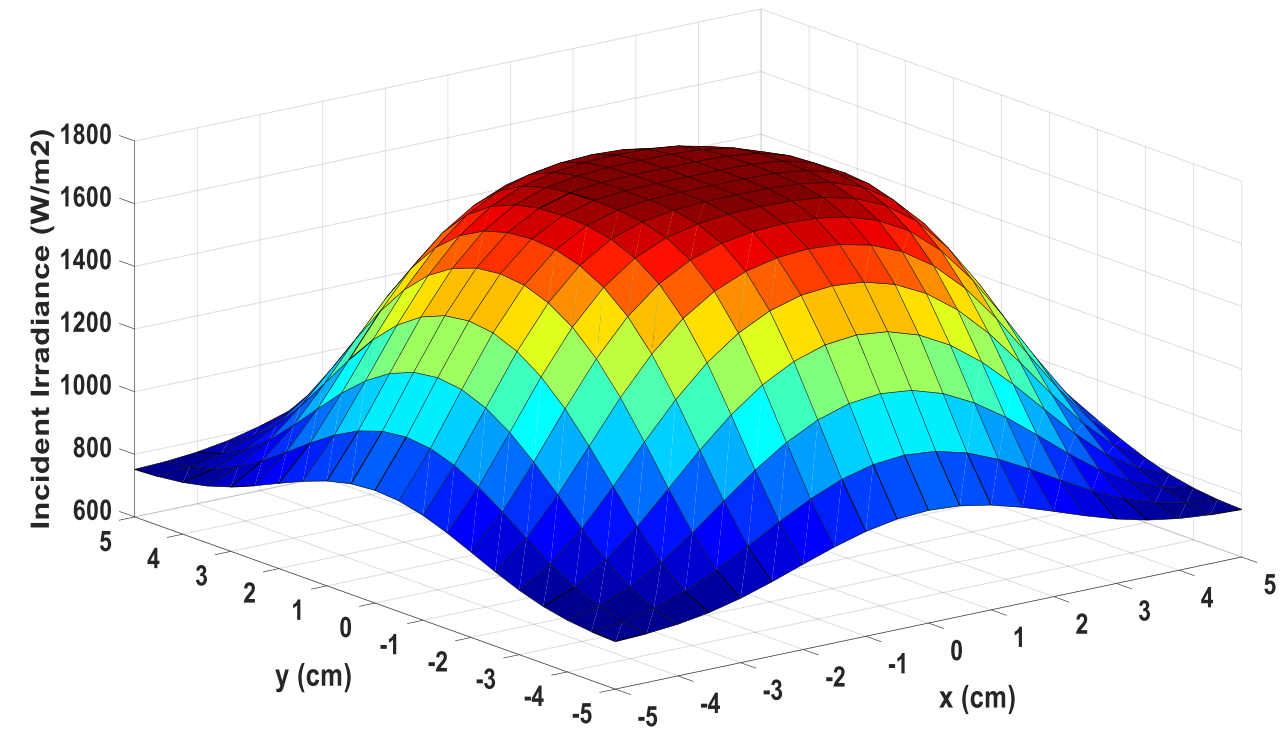

Fig. 2 The distribution of solar radiation over the top surface of the cell considered for the calculations 


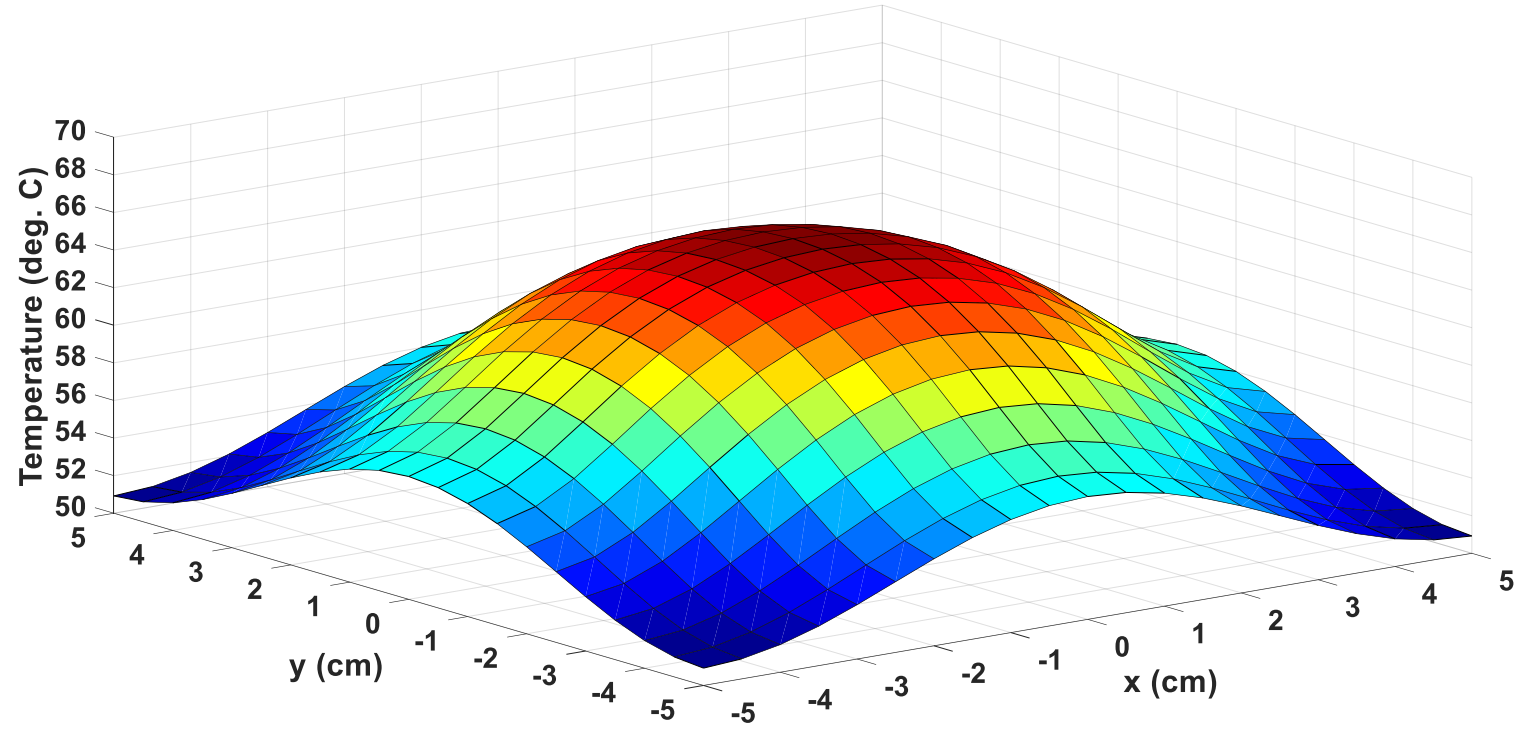

(a) Current Work

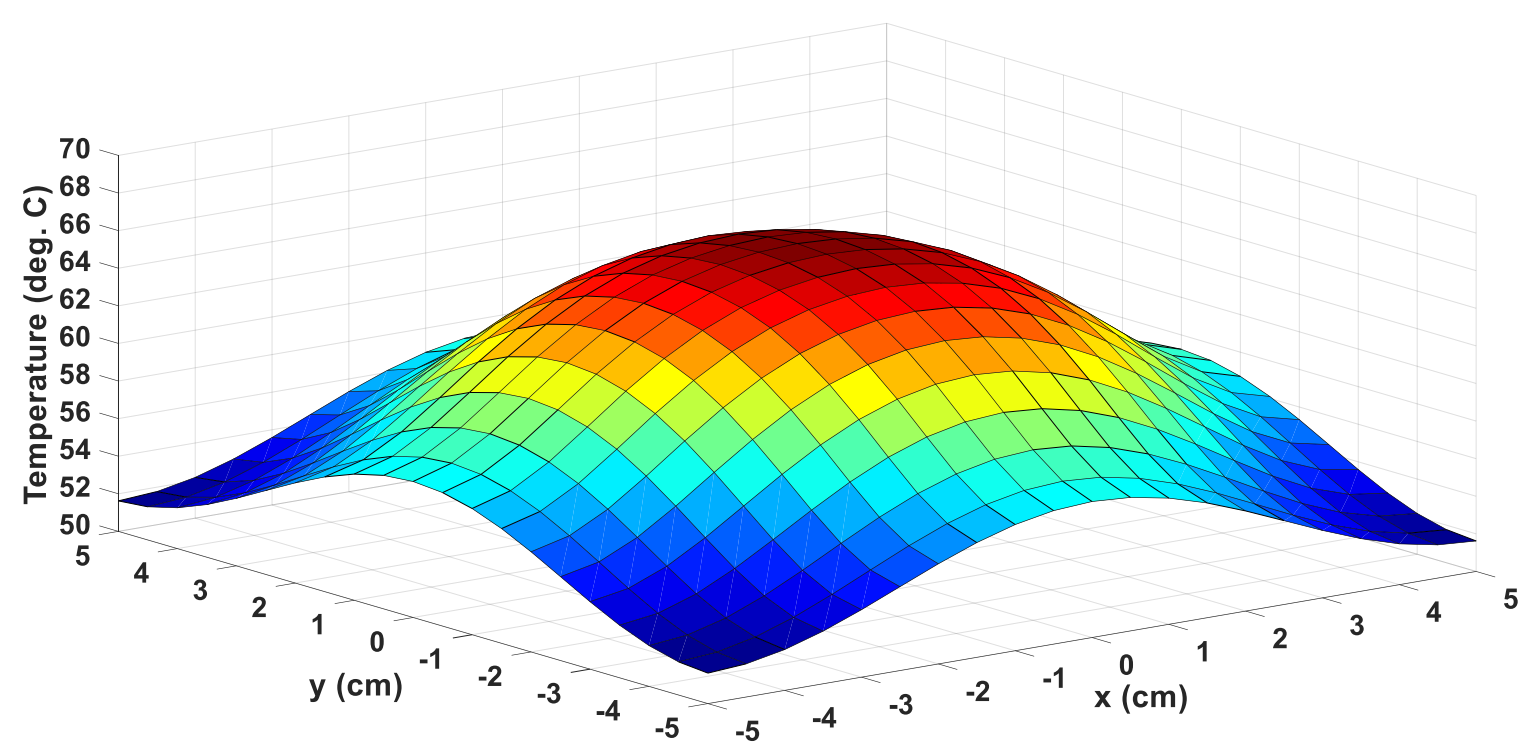

(b) Bonacina and Comini [35]

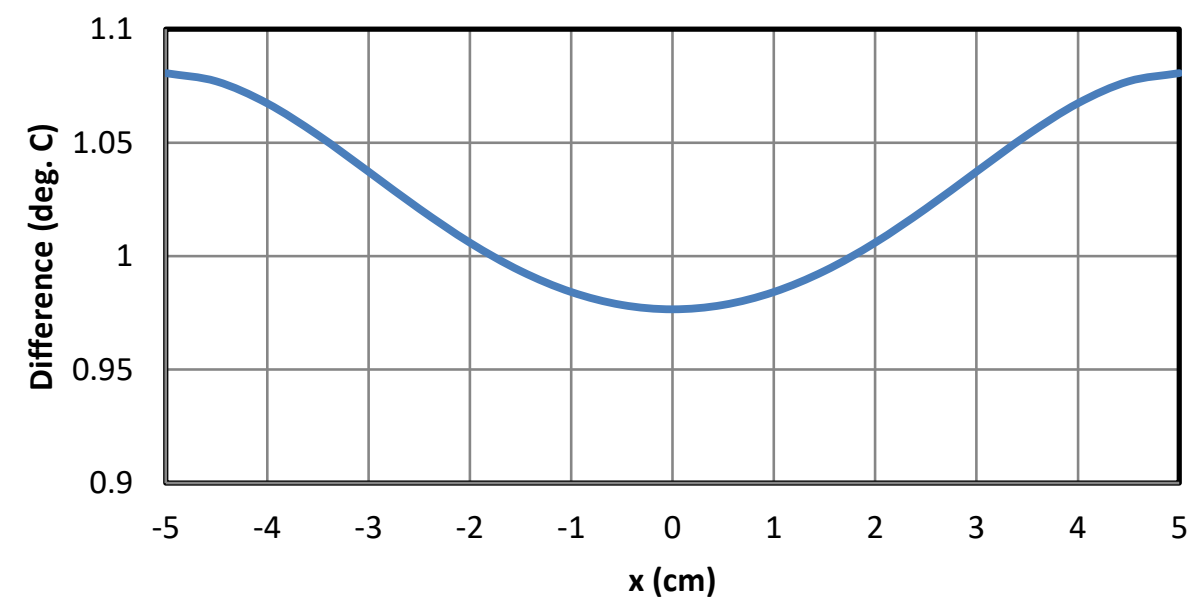

(c)Difference of temperature values $($ at $y=0)$ between plot $(a)$ and plot $(b)$

Fig. 3 Comparison of the temperature distribution computed using analytical expression of current work with that of Bonacina and Comini [35] 


\section{Results and Discussion}

296 In the current work, the studied cells are made to undergo various wind-azimuthal, wind speeds and 297 inclination of system. The non-uniform temperature distributions and the corresponding cell efficiencies 298 are computed. The specifications of the studied cells are given in Table 1.

Table 1 Specifications of studied cells

\begin{tabular}{|l|l|l|l|}
\hline & Mono-Si & DSSC [19] & Perovskite [13] \\
\hline $\begin{array}{l}\text { Name and thickness } \\
\text { of first covering }\end{array}$ & $\begin{array}{l}\text { Glass } \\
(3 \mathrm{~mm})\end{array}$ & $\begin{array}{l}\text { Glass } \\
(3 \mathrm{~mm})\end{array}$ & $\begin{array}{l}\text { Glass } \\
(3 \mathrm{~mm})\end{array}$ \\
\hline $\begin{array}{l}\text { Name and thickness } \\
\text { of second covering }\end{array}$ & $\begin{array}{l}\text { EVA } \\
(0.5 \mathrm{~mm})\end{array}$ & $\begin{array}{l}\text { Dye-sensitized } \mathrm{TiO}_{2} \\
(12 \mu \mathrm{m})\end{array}$ & $\begin{array}{l}\mathrm{TiO}_{2} \\
(300 \mathrm{~nm})\end{array}$ \\
\hline $\begin{array}{l}\text { Name and thickness } \\
\text { of third covering }\end{array}$ & $\begin{array}{l}\text { Silicon } \\
(0.3 \mathrm{~mm})\end{array}$ & $\begin{array}{l}\text { Electrolyte } \\
(2 \mu \mathrm{m})\end{array}$ & $\begin{array}{l}\text { Perovskite } \\
(250 \mathrm{~nm})\end{array}$ \\
\hline $\begin{array}{l}\text { Name and thickness } \\
\text { of fourth covering }\end{array}$ & $\begin{array}{l}\text { EVA } \\
(0.5 \mathrm{~mm})\end{array}$ & $\begin{array}{l}\text { Platinum } \\
(300 \mathrm{~nm})\end{array}$ & $\begin{array}{l}\text { Spiro-OMeTAD } \\
(100 \mathrm{~nm})\end{array}$ \\
\hline $\begin{array}{l}\text { Name and thickness } \\
\text { of fifth covering }\end{array}$ & $\begin{array}{l}\text { Tedlar } \\
(0.1 \mathrm{~mm})\end{array}$ & $\begin{array}{l}\text { Glass } \\
(3 \mathrm{~mm})\end{array}$ & $\begin{array}{l}\text { Silver } \\
(1 \mu \mathrm{m})\end{array}$ \\
\hline $\begin{array}{l}\text { Efficiency } \\
\text { Correlation }\end{array}$ & $\begin{array}{l}25.3\left[1-0.0045\left(\mathrm{~T}_{\mathrm{avg}}-25\right)\right. \\
+0.085 \mathrm{ln}(\mathrm{S} / 1000)]\end{array}$ & $\begin{array}{l}11.9\left[1-0.001\left(\mathrm{~T}_{\mathrm{avg}}-40\right)\right. \\
+0.057 \mathrm{ln}(\mathrm{S} / 800)]\end{array}$ & $\begin{array}{l}22.1\left[1-0.0068\left(\mathrm{~T}_{\mathrm{avg}}-27\right)\right. \\
+0.085 \mathrm{ln}(\mathrm{S} / 1000)]\end{array}$ \\
\hline
\end{tabular}




\subsection{Effect of Wind Direction on Heat Losses}

302

303

304

305

306

307

308

The effect of wind direction on the heat losses (from the front surface of the cells) is shown in Fig. 4 keeping $\beta_{p}=45^{\circ}, \mathrm{v}_{\mathrm{w}}=4 \mathrm{~m} / \mathrm{s}$, and $S=1000 \mathrm{~W} / \mathrm{m}^{2}$. It can be seen that as wind-azimuthal decreases from $90^{\circ}$ to $0^{\circ}$, the heat loss from the front of the cell increases from 371 to $472 \mathrm{~W} / \mathrm{m}^{2}$ for mono-Si cell, 314 to $407 \mathrm{~W} / \mathrm{m}^{2}$ for DSSC and 279 to $358 \mathrm{~W} / \mathrm{m}^{2}$ for perovskite. This effect can be explained as follows: when wind-azimuthal angle is high, the wind strikes the surface almost tangentially as shown in Fig. 5a. On the other hand, when wind azimuth angle is low, the wind strikes the surface almost normally (perpendicularly) as shown in Fig. 5b. Thus, for former case, the projected surface area coming in the path of wind is lesser as compared to the latter case of low wind azimuth angle. The lesser projected surface area in the path of wind leads to lesser heat transfer from the surface of the cell to the surroundings resulting in lesser heat losses which can also be seen from the results of Khanna et al. [31].

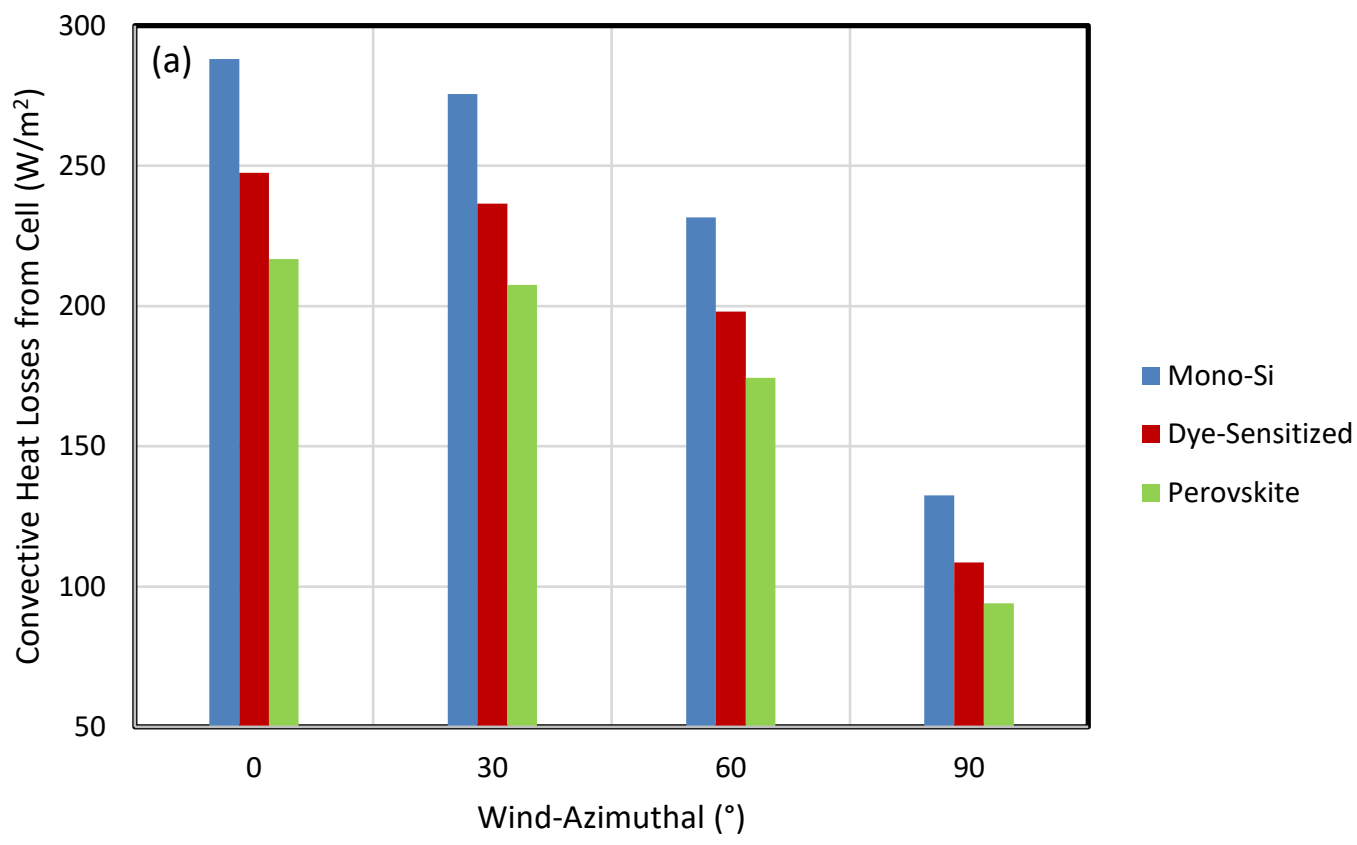




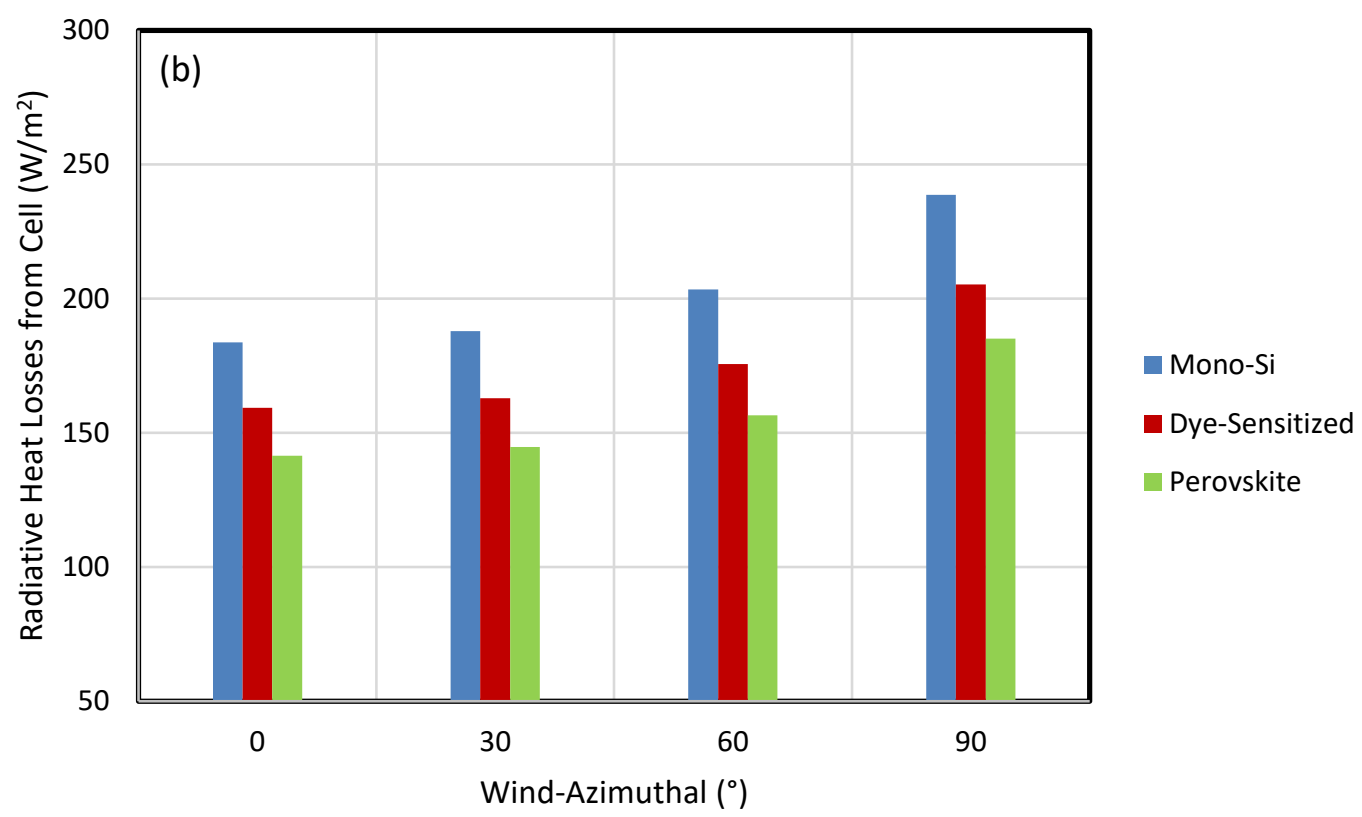

315

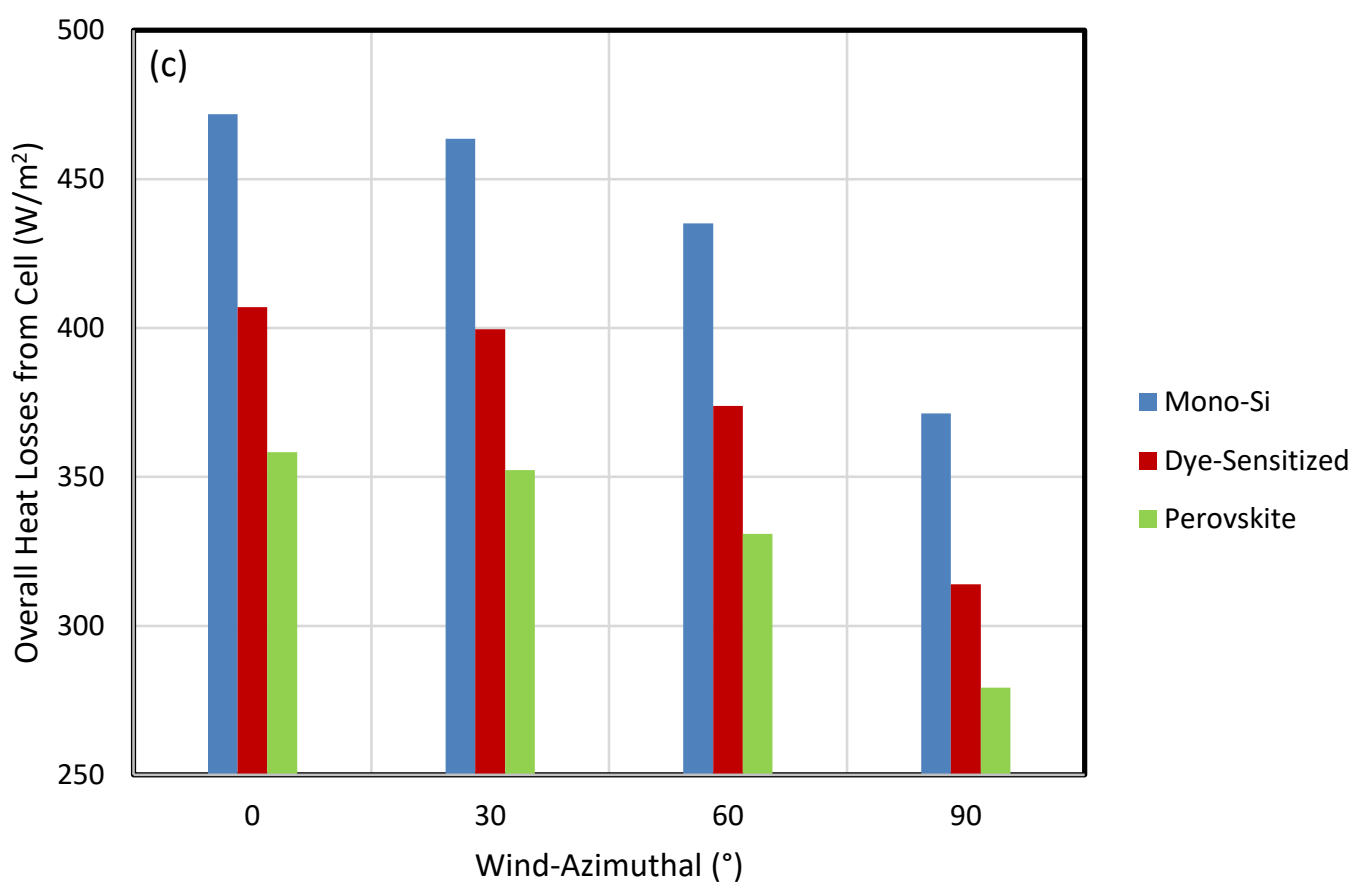

Fig. 4 Effect of wind direction on the heat losses from the front of the cells 


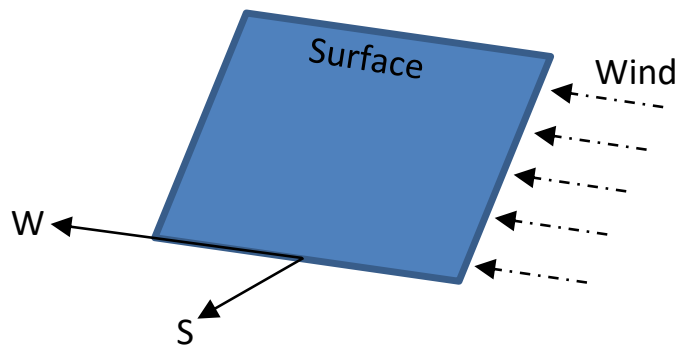

(a)

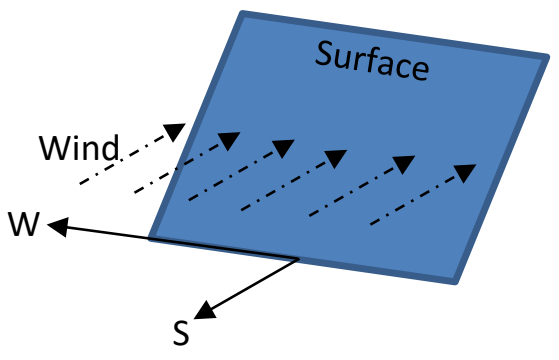

(b)

318

Fig. 5 (a) Case of high wind azimuth angle and (b) case of low wind azimuth angle 


\subsection{Effect of Wind Speed on Heat Losses}

321 The effect of wind speed on the heat losses from the front surface of the cells is shown in Fig.

3226 keeping $\beta_{p}=45^{\circ}, \gamma_{\mathrm{w}}=0^{\circ}$ and $S=1000 \mathrm{~W} / \mathrm{m}^{2}$. It can be seen that as wind speed increases from

$3230.2 \mathrm{~m} / \mathrm{s}$ to $5 \mathrm{~m} / \mathrm{s}$, the heat loss from the cell increases from $445 \mathrm{~W} / \mathrm{m}^{2}$ to $473 \mathrm{~W} / \mathrm{m}^{2}$ for mono-Si

324 cell, $377 \mathrm{~W} / \mathrm{m}^{2}$ to $409 \mathrm{~W} / \mathrm{m}^{2}$ for DSSC and $341 \mathrm{~W} / \mathrm{m}^{2}$ to $359 \mathrm{~W} / \mathrm{m}^{2}$ for perovskite. It is due to

325 the fact that as the wind speed increases, the rate of wind hitting the surface increases as shown

326 in Fig. 7. It increases the effect of forced convection. Thus, as the wind speed increases, the rate

327 of heat transfer (from the surface of the cell to the surroundings) increases which leads to higher

328 heat losses from the cell which can also be seen from the results of Armstrong and Hurley [36].

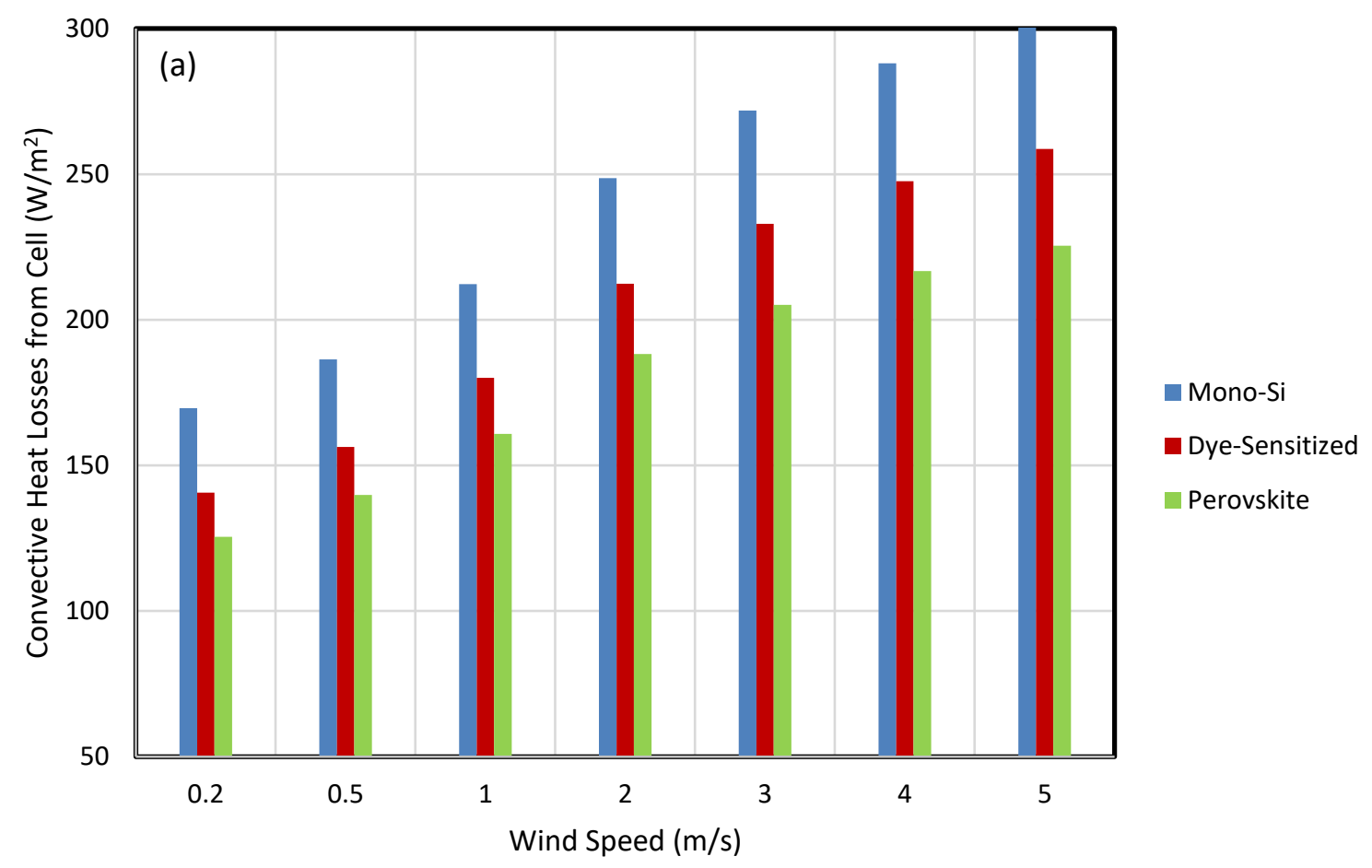




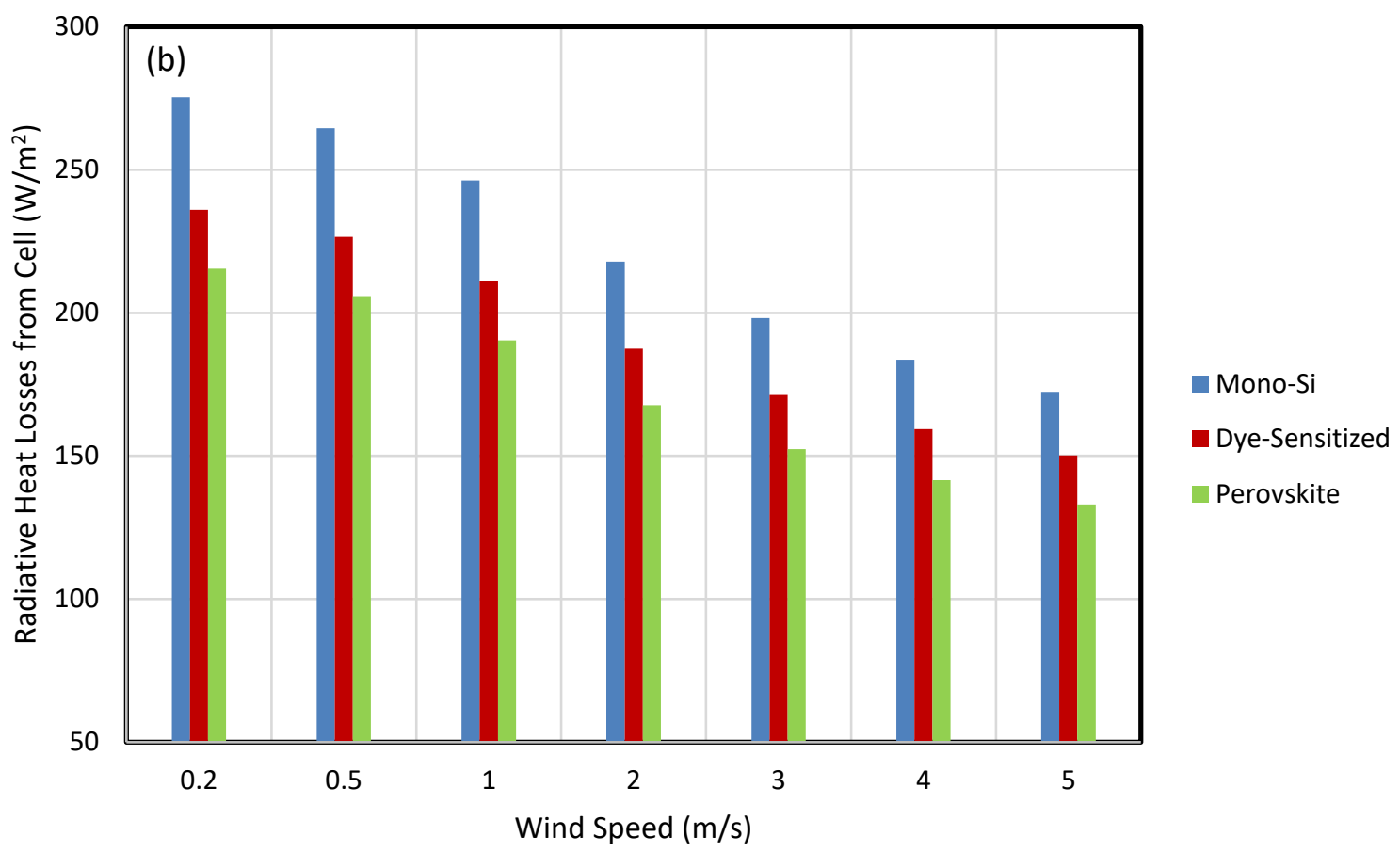

330

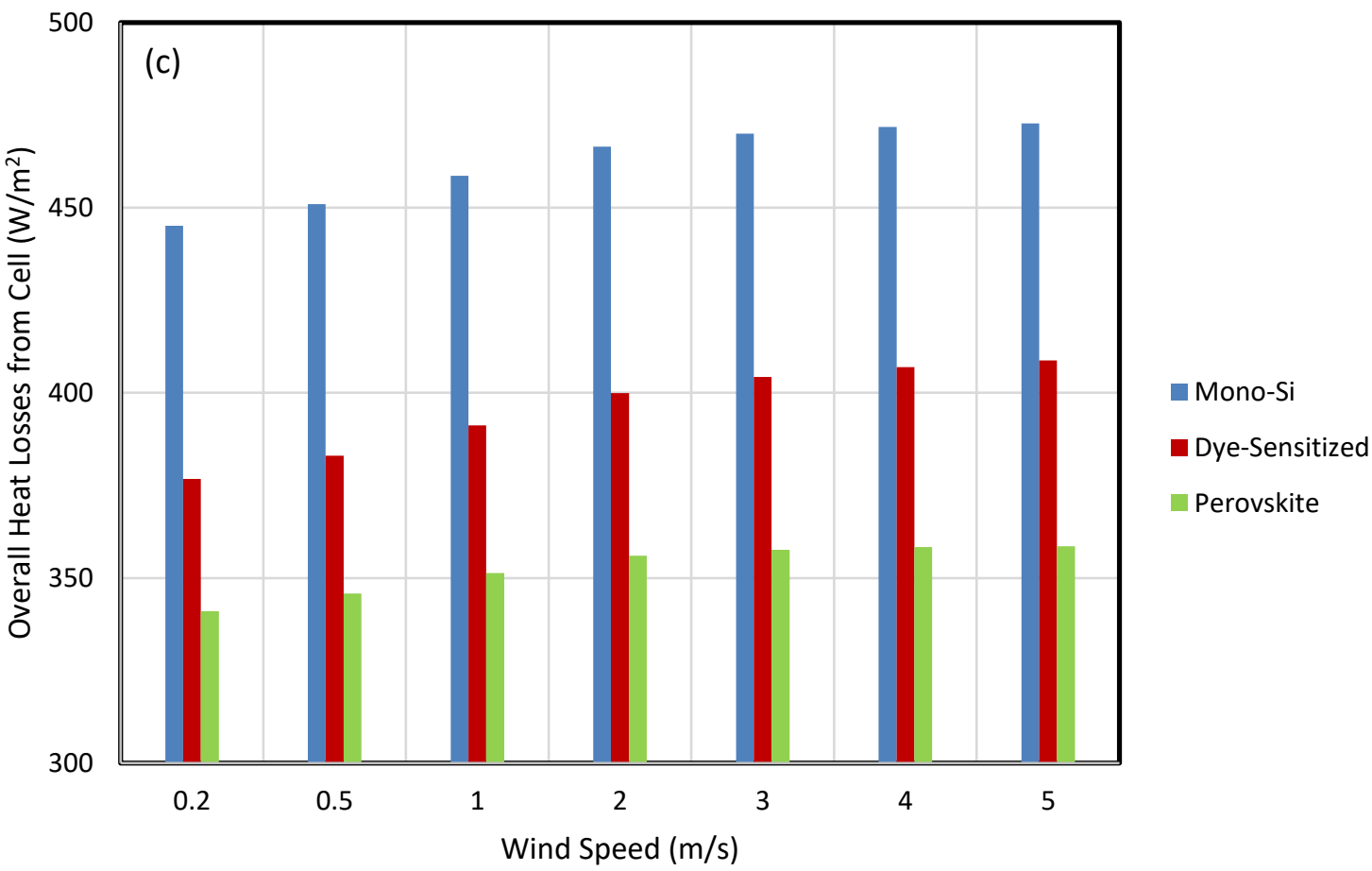

331

Fig. 6 Effect of wind speed on the heat losses from the front of the cells 


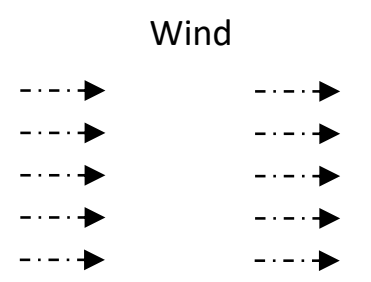

Surface

(a)

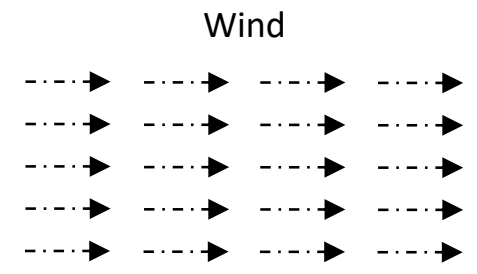

Surface

(a)

Fig. 7 (a) Case of low wind speed and (b) case of high wind speed

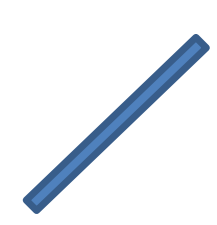

335 


\subsection{Effect of Inclination Angle on Heat Losses}

337 The effect of inclination angle on the heat losses from the front surface of the cells is shown in 338 Fig. 8 keeping $\gamma_{\mathrm{w}}=0^{\circ}, \mathrm{v}_{\mathrm{w}}=4 \mathrm{~m} / \mathrm{s}$ and $S=1000 \mathrm{~W} / \mathrm{m}^{2}$. It can be seen that as inclination angle 339 decreases from $90^{\circ}$ to $0^{\circ}$, the heat loss from the cell decreases from 486 to $391 \mathrm{~W} / \mathrm{m}^{2}$ for mono340 Si cell, 419 to $331 \mathrm{~W} / \mathrm{m}^{2}$ for DSSC and 368 to $294 \mathrm{~W} / \mathrm{m}^{2}$ for perovskite. This effect can be explained as follows: when inclination angle of the system is very high, the wind hits the surface almost normally (perpendicularly) as shown in Fig. 9a. On the other hand, when inclination angle is low, the wind hits the surface almost tangentially as shown in Fig. 9b. Thus, for former case, the projected surface area coming in the path of wind is larger as compared to the latter case of low inclination angle. The larger projected surface area in the path of wind leads to higher rate of heat transfer from the surface of the cell to the surroundings resulting in higher heat losses which can also be seen from the results of Gallero et al. [28].

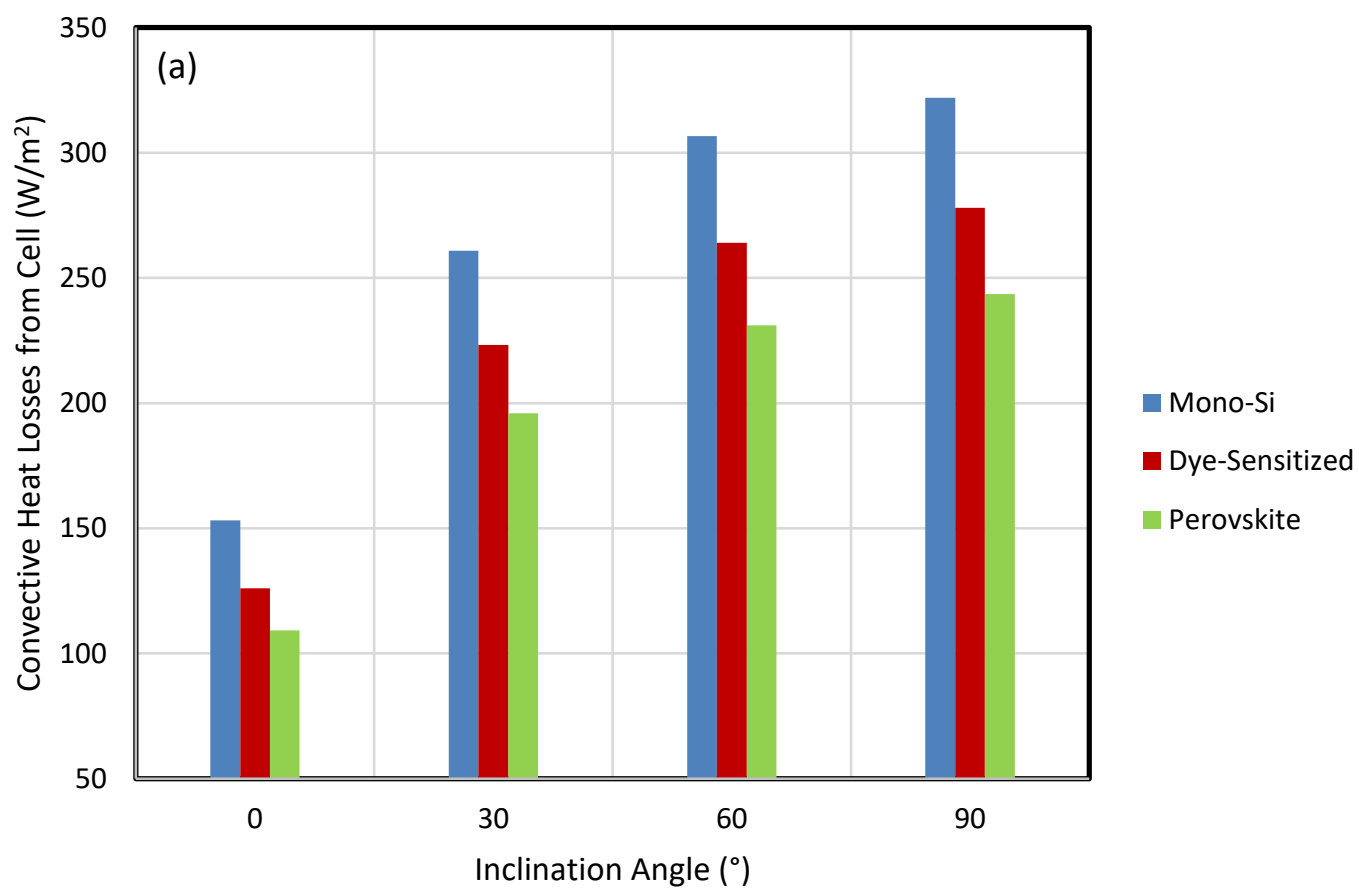




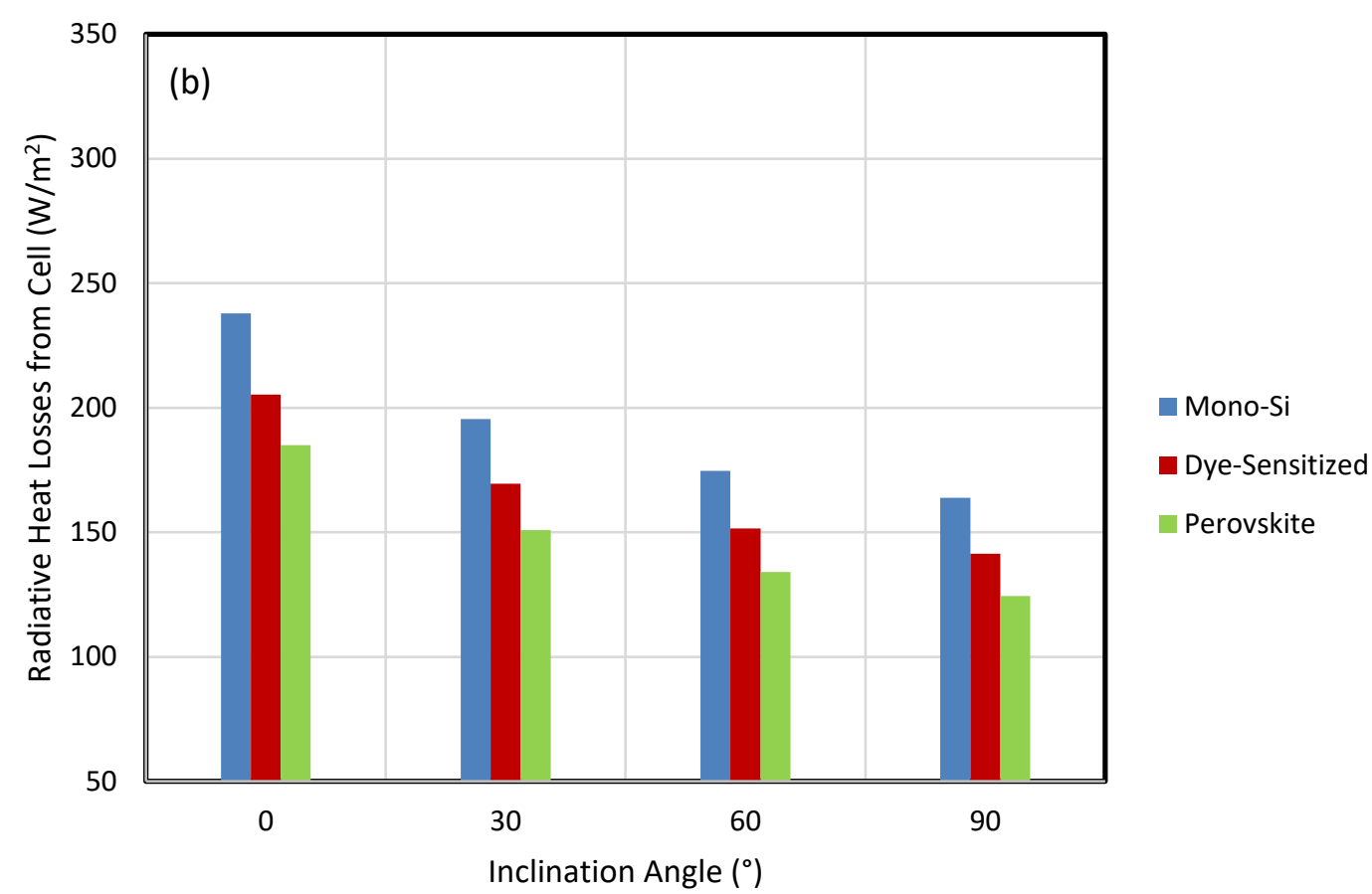

350

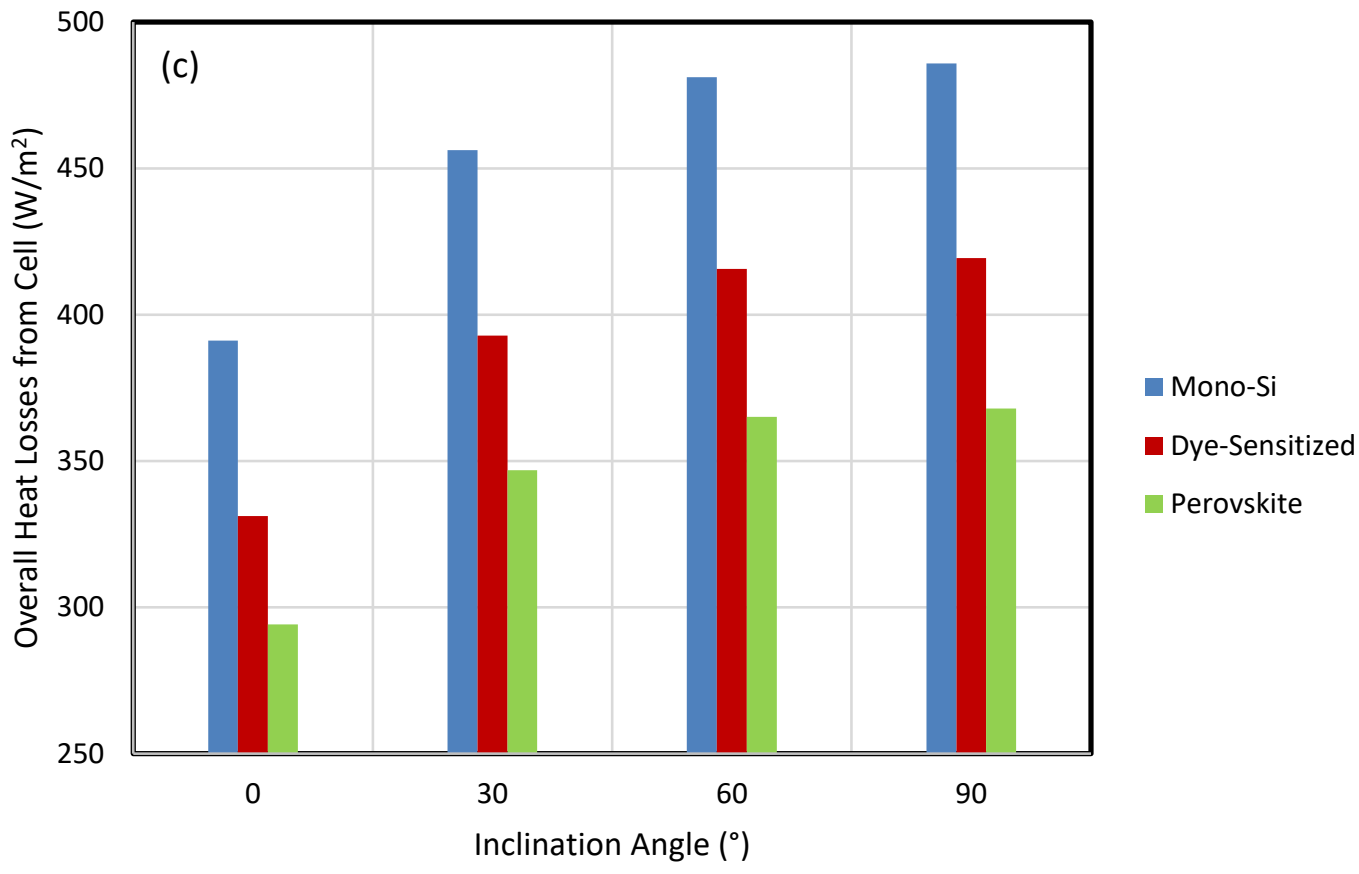

Fig. 8 Effect of inclination angle on the heat losses from the front of the cells 


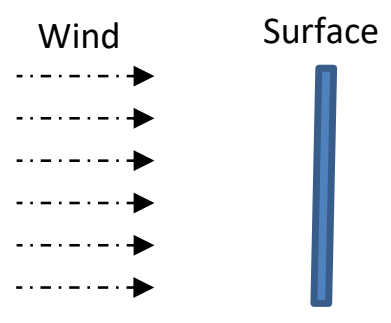

(a)

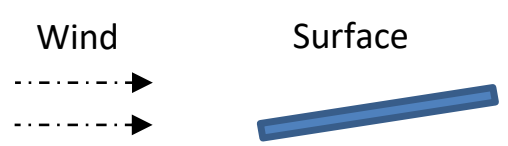

(b)

Fig. $9($ a) Case of high inclination angle and (b) case of low inclination angle 


\subsection{Effect of Solar Irradiance on Heat Losses}

356

The effect of solar irradiance on the heat losses from the front surface of the cells is shown in Fig. 10 keeping $\gamma_{\mathrm{w}}=0^{\circ}, \mathrm{v}_{\mathrm{w}}=4 \mathrm{~m} / \mathrm{s}$ and $\beta_{p}=45^{\circ}$. It can be seen that as solar irradiance increases from 250 to $1000 \mathrm{~W} / \mathrm{m}^{2}$, the heat loss from the cell increases from $129 \mathrm{~W} / \mathrm{m}^{2}$ to $472 \mathrm{~W} / \mathrm{m}^{2}$ for mono-Si cell, $111 \mathrm{~W} / \mathrm{m}^{2}$ to $407 \mathrm{~W} / \mathrm{m}^{2}$ for DSSC and $99 \mathrm{~W} / \mathrm{m}^{2}$ to $358 \mathrm{~W} / \mathrm{m}^{2}$ for perovskite. Thus, the heat loss increases with increase in solar irradiance which can also be seen from the results of Armstrong and Hurley [36]. It is due to the fact that as the irradiance increases, the rate of solar energy absorption by the cell increases. It also increases the portion of solar energy that does not convert into electricity which increases the rate of heat generation in the cell resulting in higher heat losses.

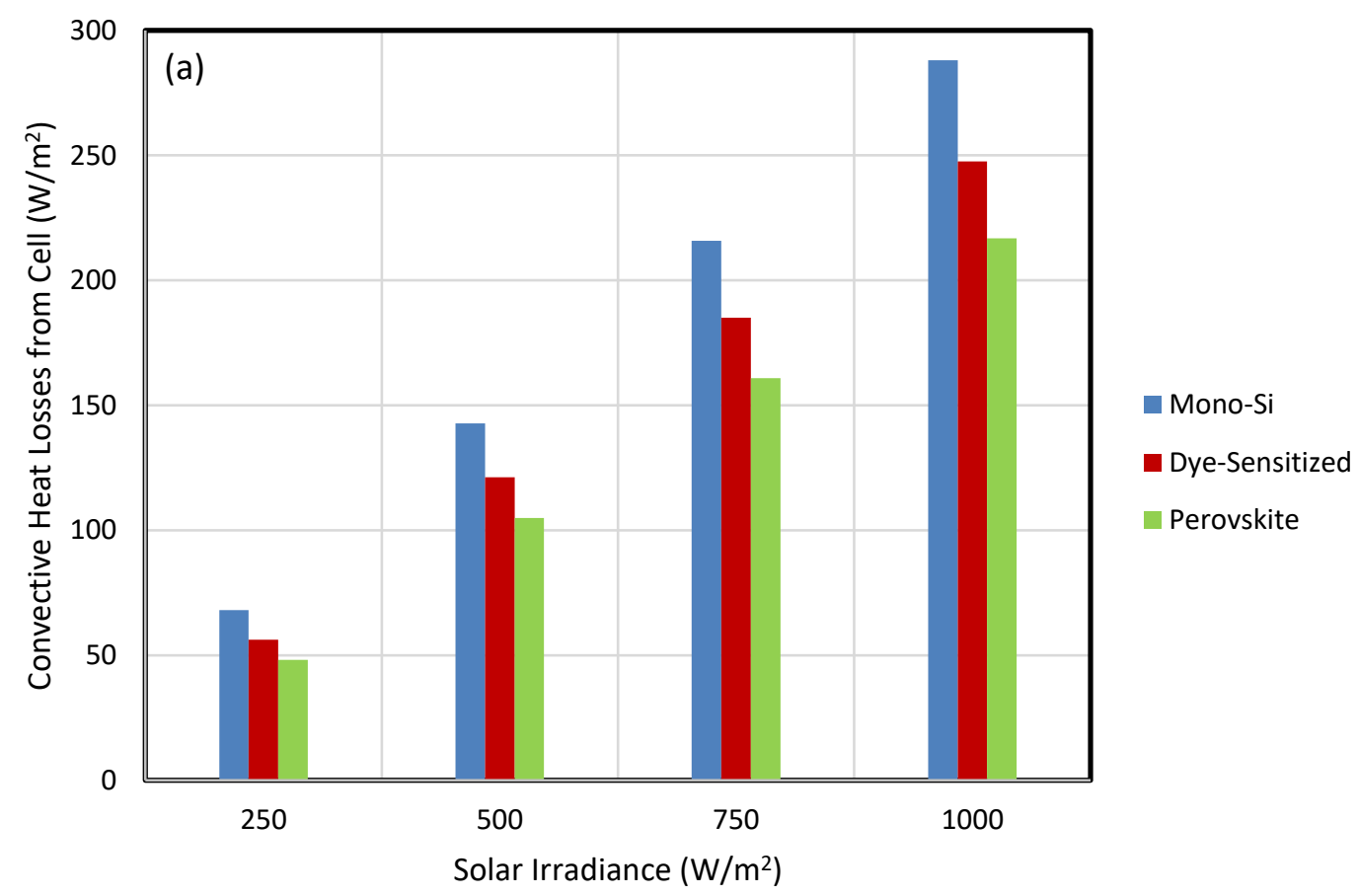




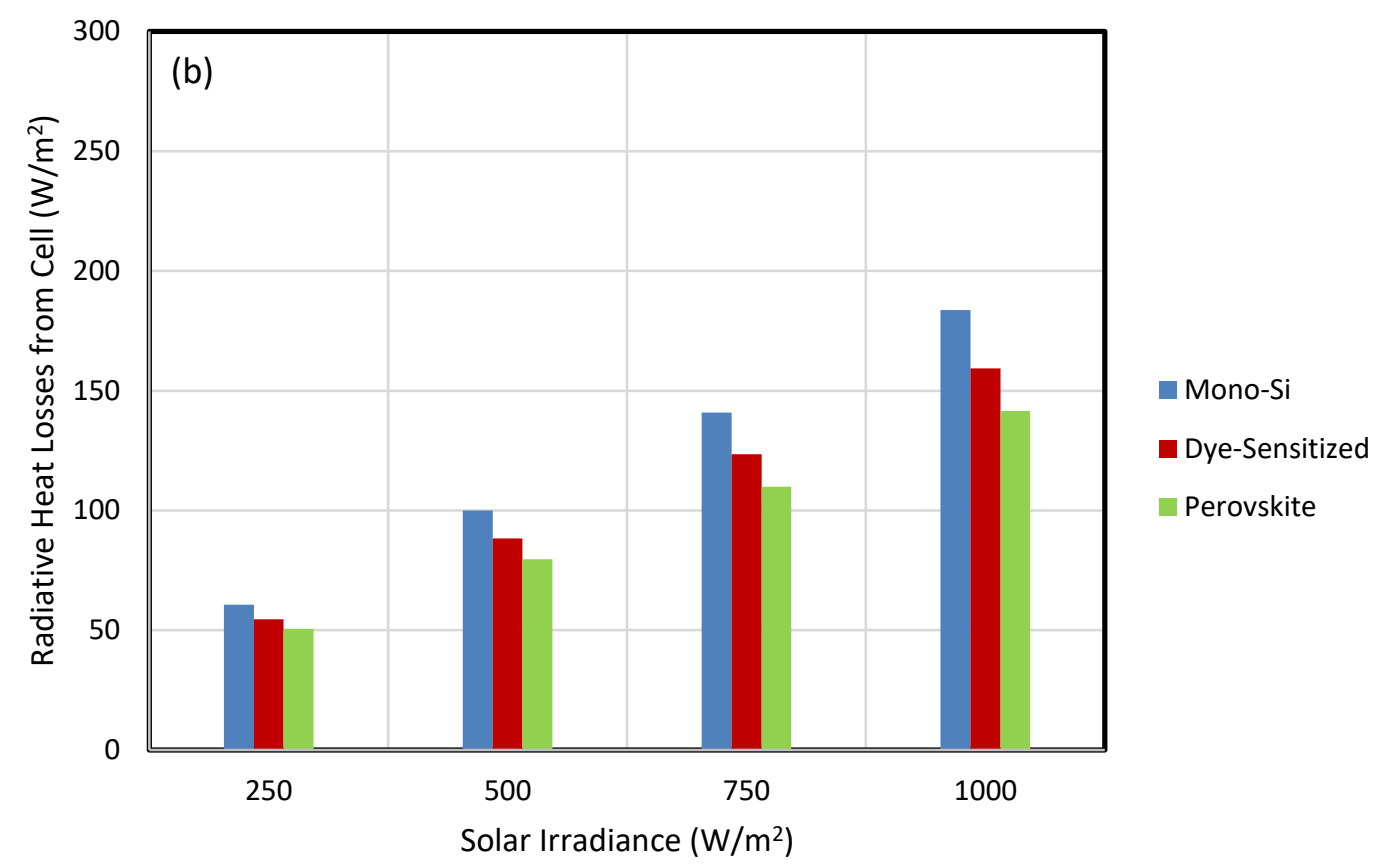

366

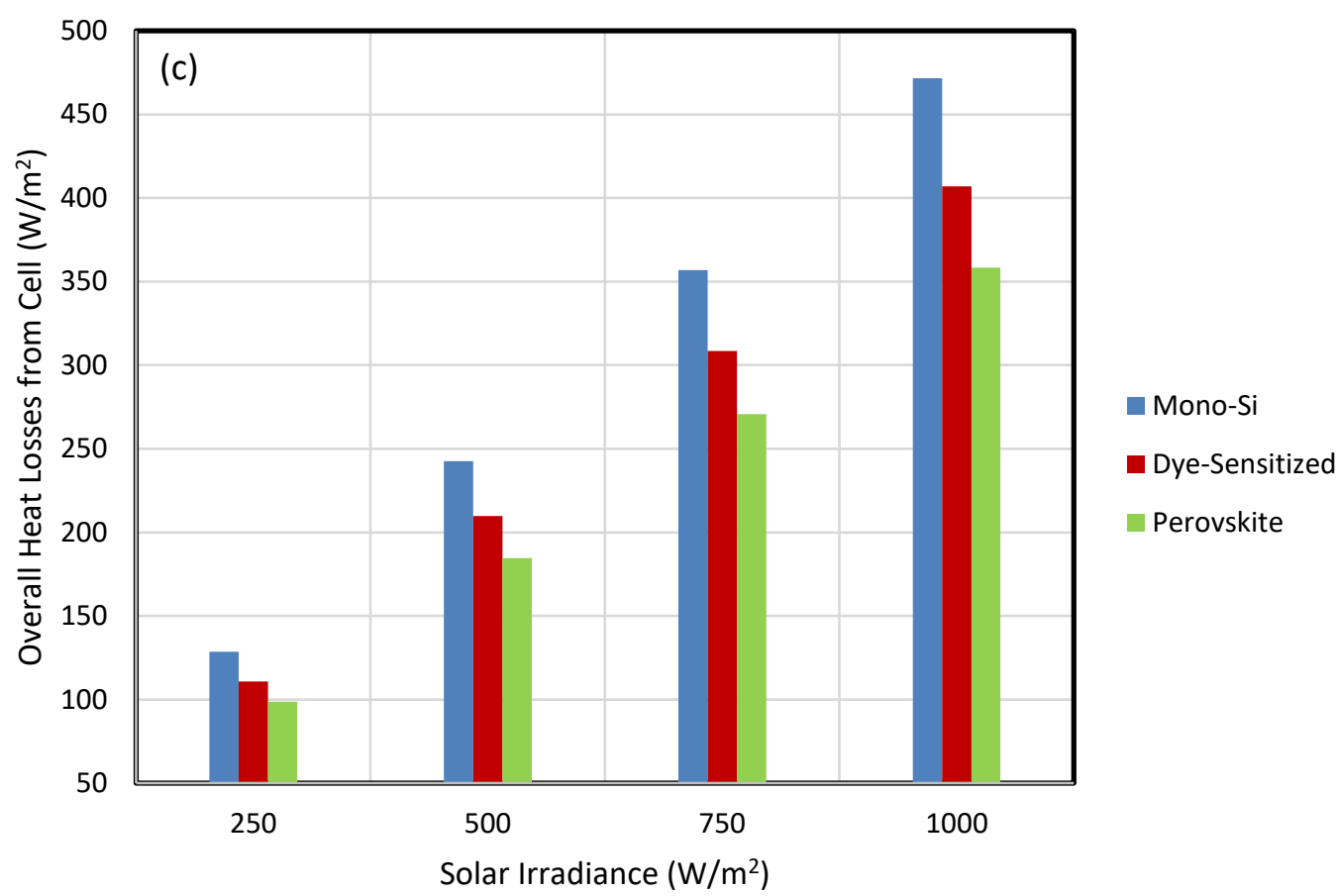

Fig. 10 Effect of solar irradiance on the heat losses from the front of the cells 


\subsection{Effect of Wind Direction on Cell Temperature}

370 The effect of wind direction on the temperature distributions is shown in Fig. 11 keeping $\beta_{p}=$

$37145^{\circ}, S=1000 \mathrm{~W} / \mathrm{m}^{2}$ and $\mathrm{v}_{\mathrm{w}}=4 \mathrm{~m} / \mathrm{s}$. The corresponding variations in the maximum temperature

372 of the cells are plotted in Fig. 12. It can be seen that as azimuthal rises to $90^{\circ}$, the maximum

373 temperature point on the surface of the cell rises from 66 to $75^{\circ} \mathrm{C}$ for mono-Si cell, 61 to $68^{\circ} \mathrm{C}$

374 for DSSC and 56 to $64^{\circ} \mathrm{C}$ for perovskite. Thus, the cell temperature increases with increase in

375 wind-azimuthal which can also be seen from the results of Vasel and Iakovidis [8]. It is due to

376 the fact that when wind-azimuthal is very high, the heat losses from the cells are lesser which

377 can be seen from Fig. 4. Thus, larger wind azimuthal leads to larger accumulation of heat in the

378 cell resulting in higher cell temperature.

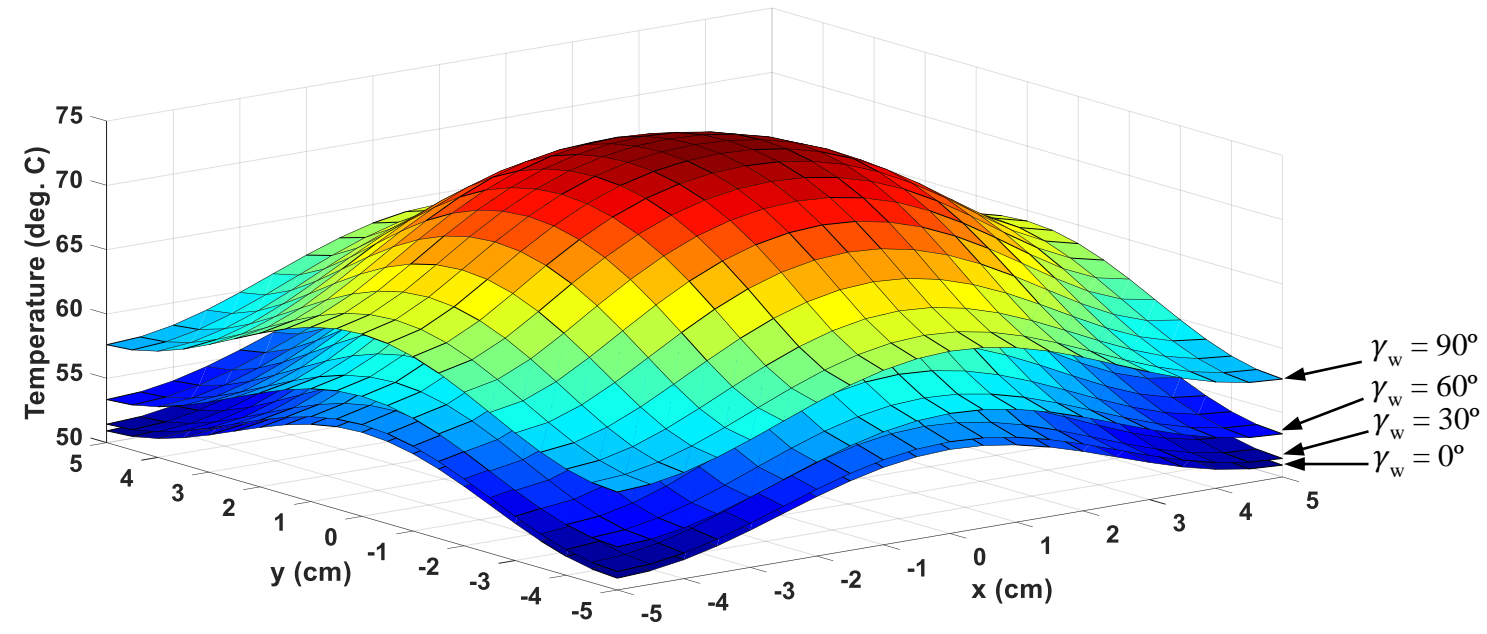

(a) Monocrystalline silicon solar cell 
381

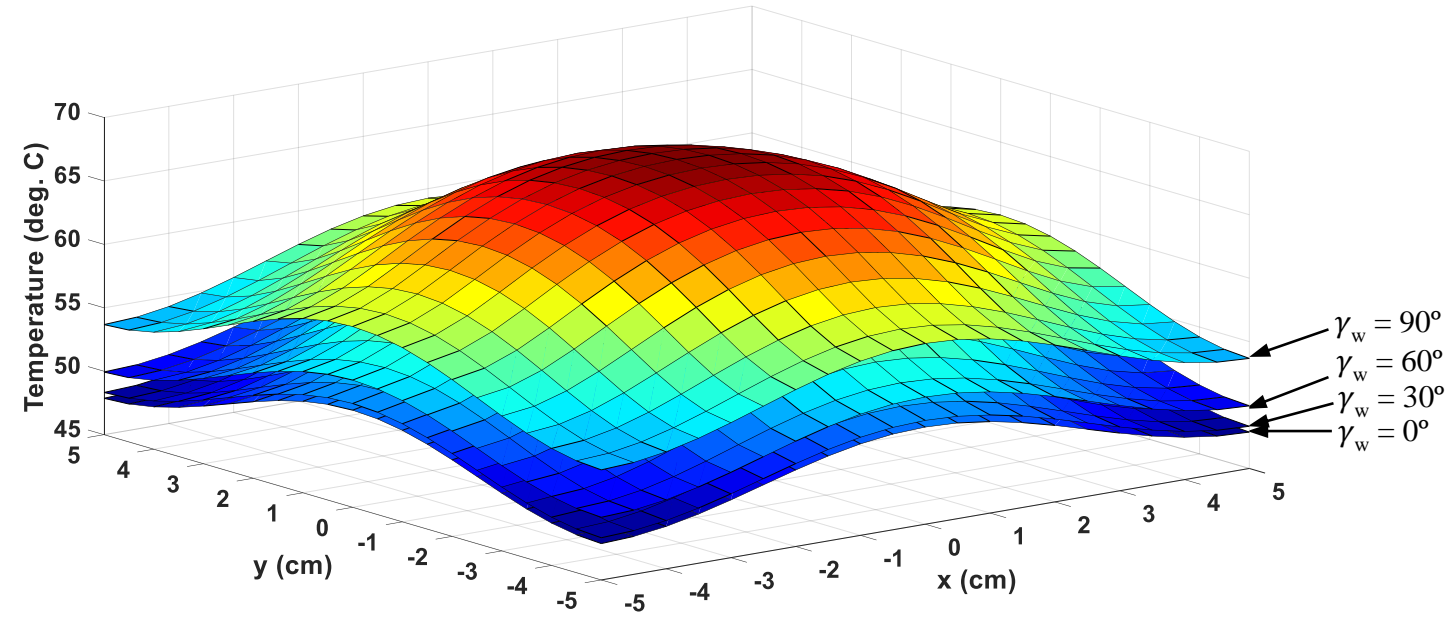

(b) Dye-sensitized solar cell

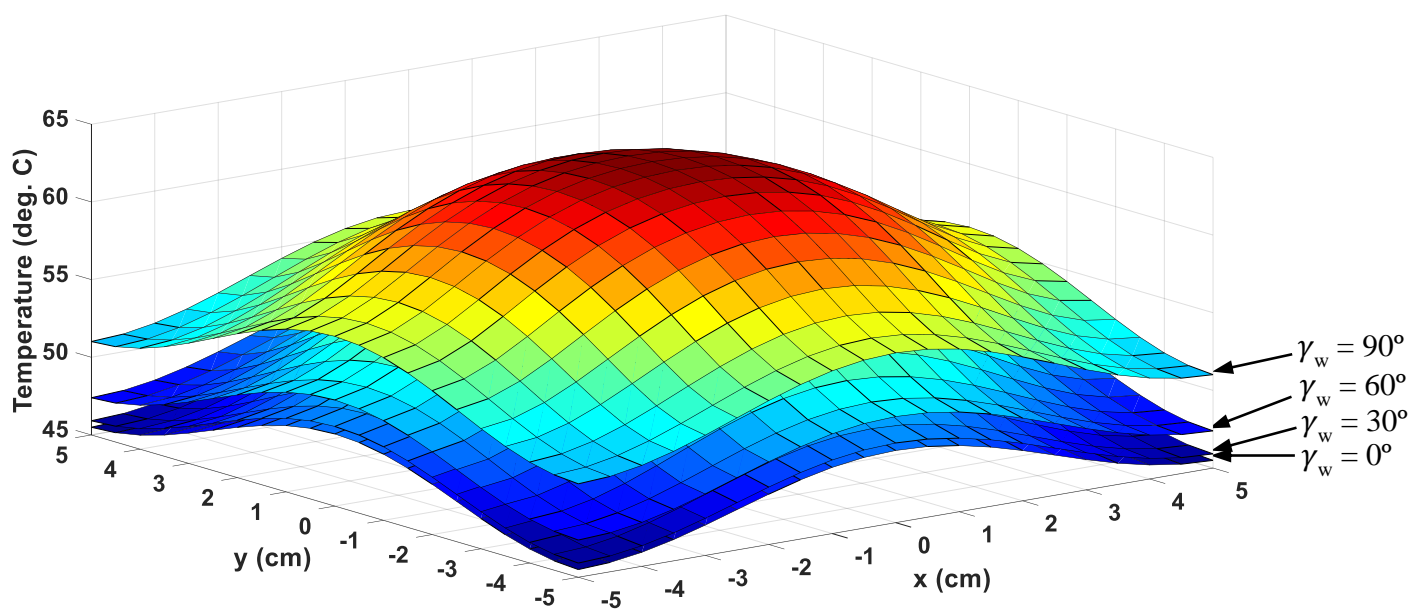

(c) Perovskite solar cell

Fig. 11 Effect of wind direction on the temperature distributions of the cells

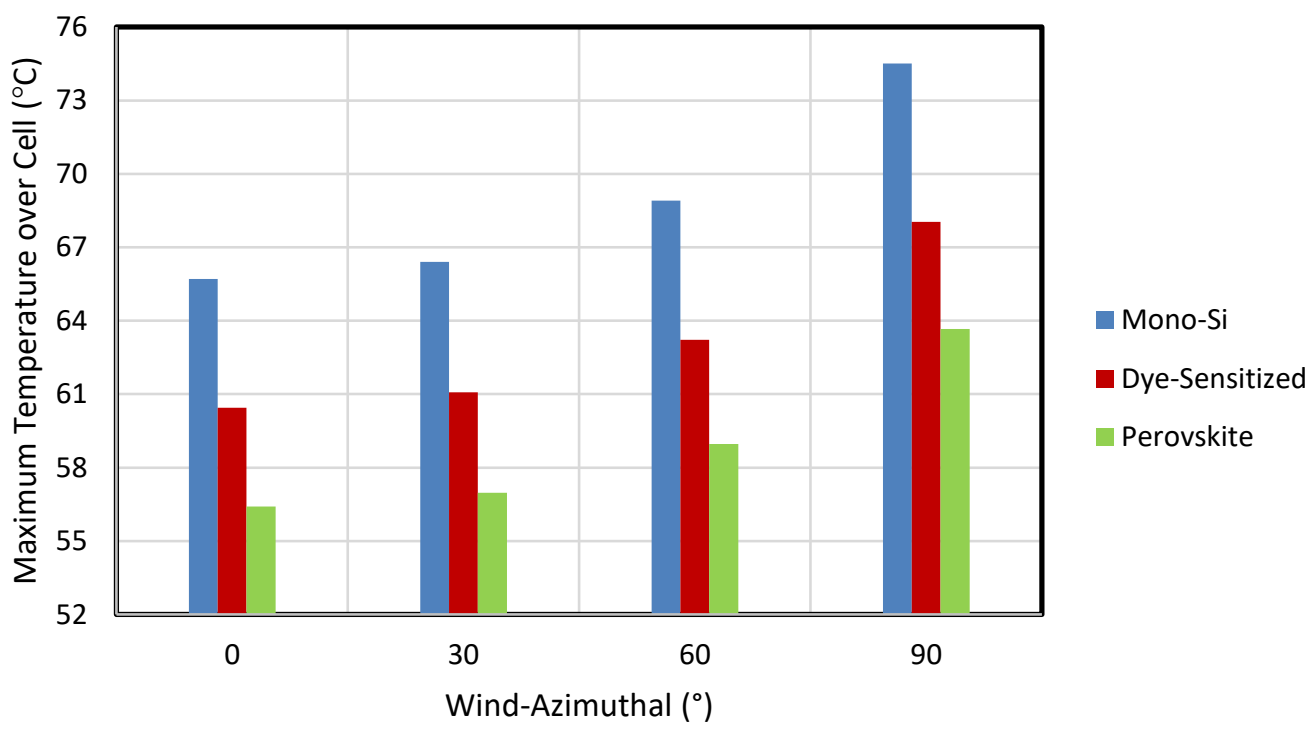

Fig. 12 Effect of wind direction on the maximum temperature over the cells 


\subsection{Effect of Wind Speed on Cell Temperature}

389 The effect of wind speed on the temperature distributions is shown in Fig. 13 keeping $\beta_{p}=45^{\circ}$, $390 S=1000 \mathrm{~W} / \mathrm{m}^{2}$ and $\gamma_{\mathrm{w}}=0^{\circ}$. The corresponding variations in the maximum temperature of the 391 cells are plotted in Fig. 14. It can be seen that as wind speed increases from $0.5 \mathrm{~m} / \mathrm{s}$ to $5 \mathrm{~m} / \mathrm{s}$, the maximum temperature point on the surface of the cell drops from 79 to $64^{\circ} \mathrm{C}$ for mono-Si cell, 72 to $59^{\circ} \mathrm{C}$ for DSSC and 67 to $55^{\circ} \mathrm{C}$ for perovskite. Thus, the cell temperature decreases with increase in wind speed which can be seen from the results of Goossens et al. [4]. It is due to the fact that when wind speed is high, the heat losses from the cells are higher which can be seen from Fig. 6. Thus, higher wind speed leads to lesser accumulation of heat in the cell resulting in lower cell temperature.

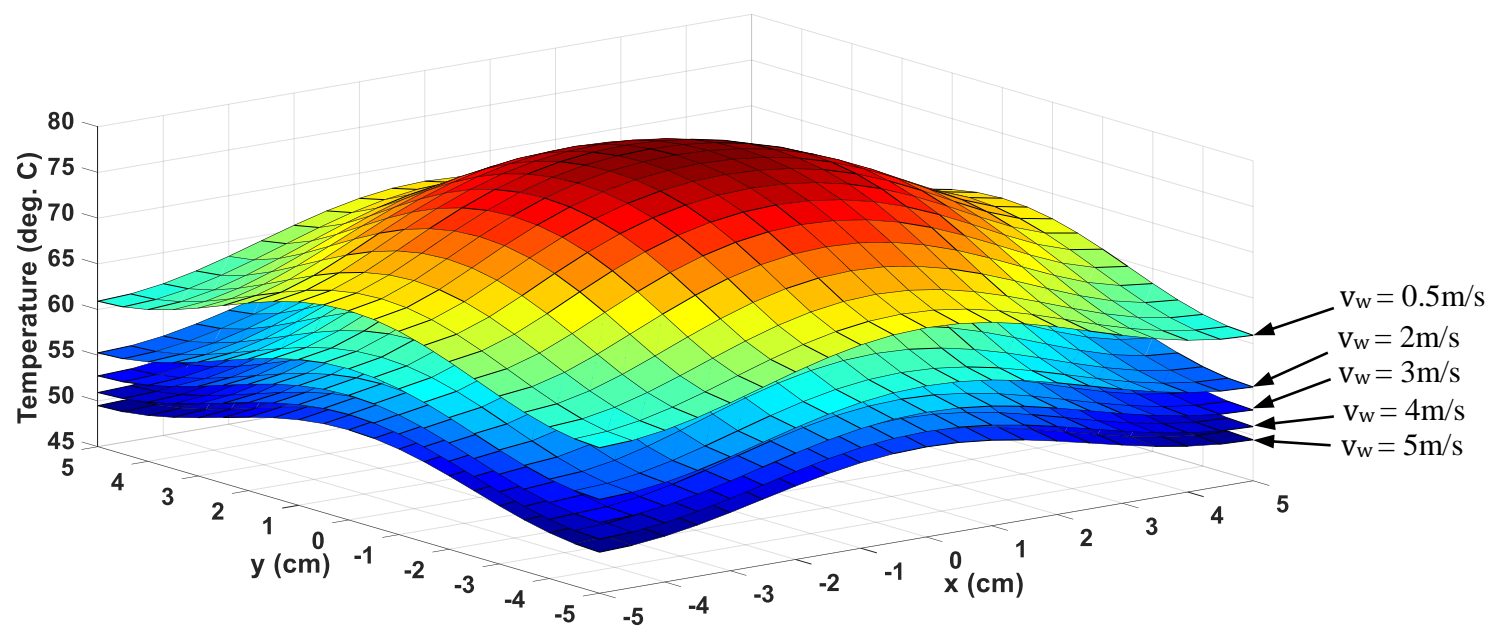


400 401

402

403

404

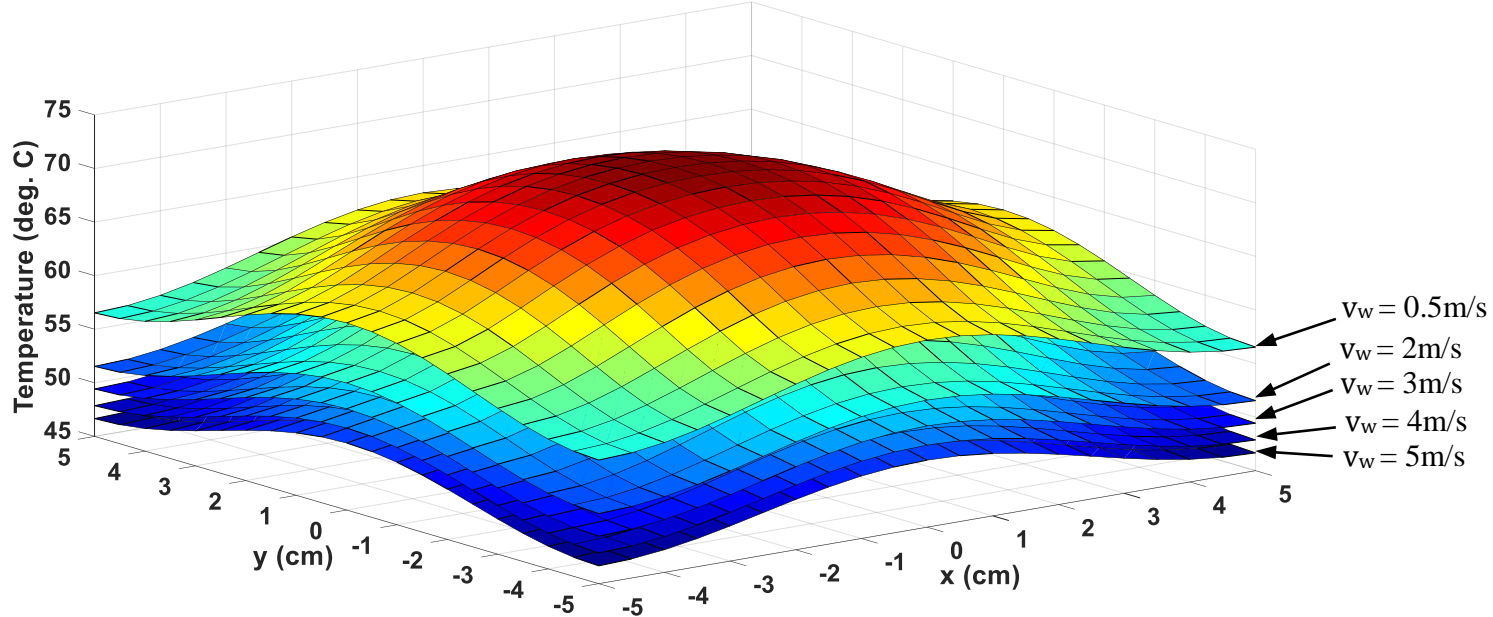

(b) Dye-sensitized solar cell

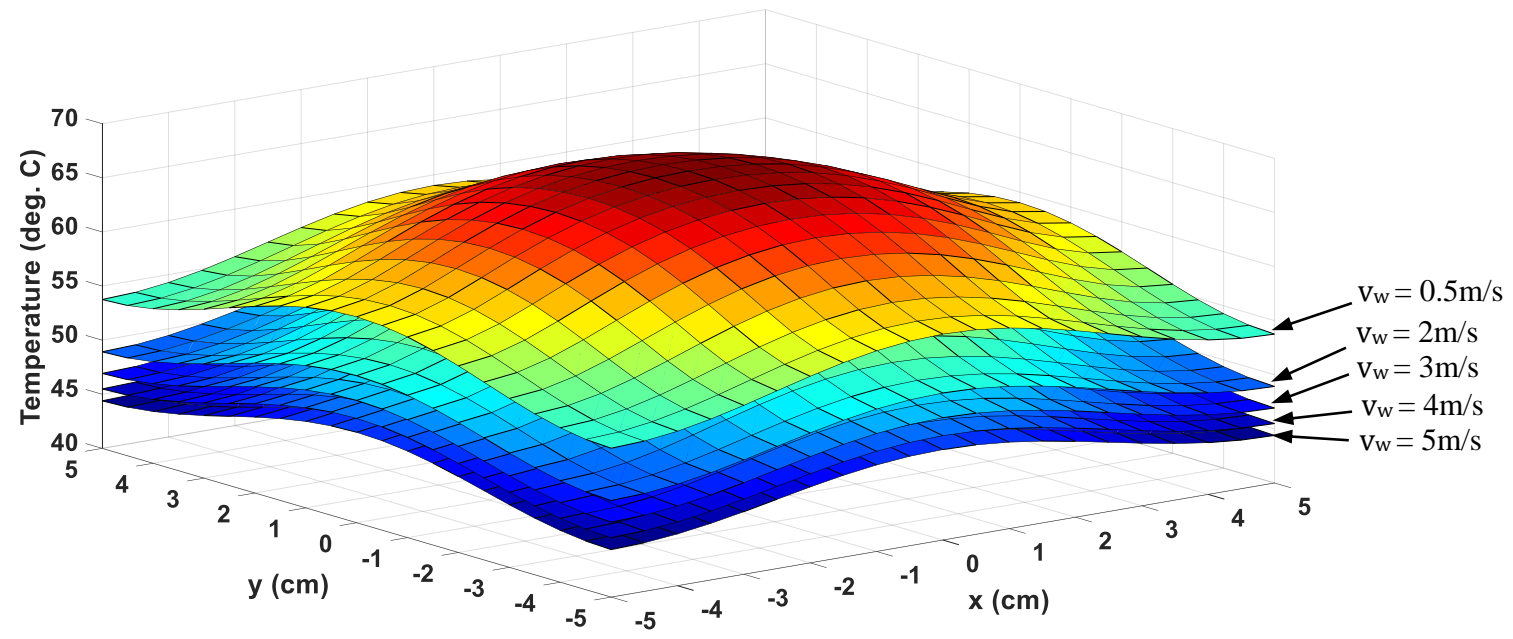

(c) Perovskite solar cell

Fig. 13 Effect of wind speed on the temperature distributions of the cells

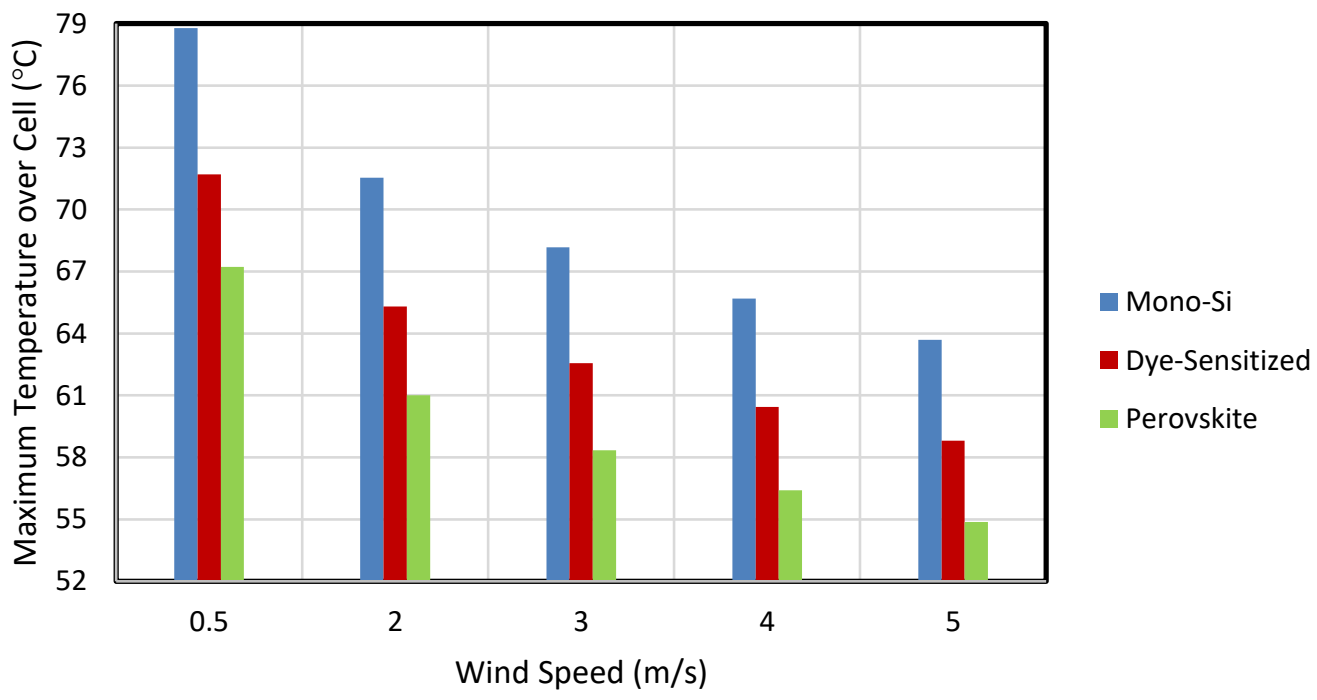

Fig. 14 Effect of wind speed on the maximum temperature over the cells 


\subsection{Effect of Inclination Angle on Cell Temperature}

408

409

410

411

412

413

414

415

416

The effect of inclination angle on the temperature distributions is shown in Fig. 15 keeping $\beta_{p}$ $=45^{\circ}, S=1000 \mathrm{~W} / \mathrm{m}^{2}$ and $\gamma_{\mathrm{w}}=0^{\circ}$. The corresponding variations in the maximum temperature of the cells are plotted in Fig. 16. It can be seen that as inclination angle raises to $90^{\circ}$, the maximum temperature point on the surface of the cell decreases from 74 to $64^{\circ} \mathrm{C}$ for mono-Si cell, $67^{\circ} \mathrm{C}$ to $59^{\circ} \mathrm{C}$ for $\mathrm{DSSC}$ and $63^{\circ} \mathrm{C}$ to $55^{\circ} \mathrm{C}$ for perovskite. Thus, the cell temperature decreases with increase in inclination angle which can also be seen from the results of Gallero et al. [28]. It is due to the fact that for higher inclination, the heat losses from the cells are higher which can be seen from Fig. 8. Thus, higher inclination angle leads to lesser accumulation of heat in the cell resulting in lower cell temperature.

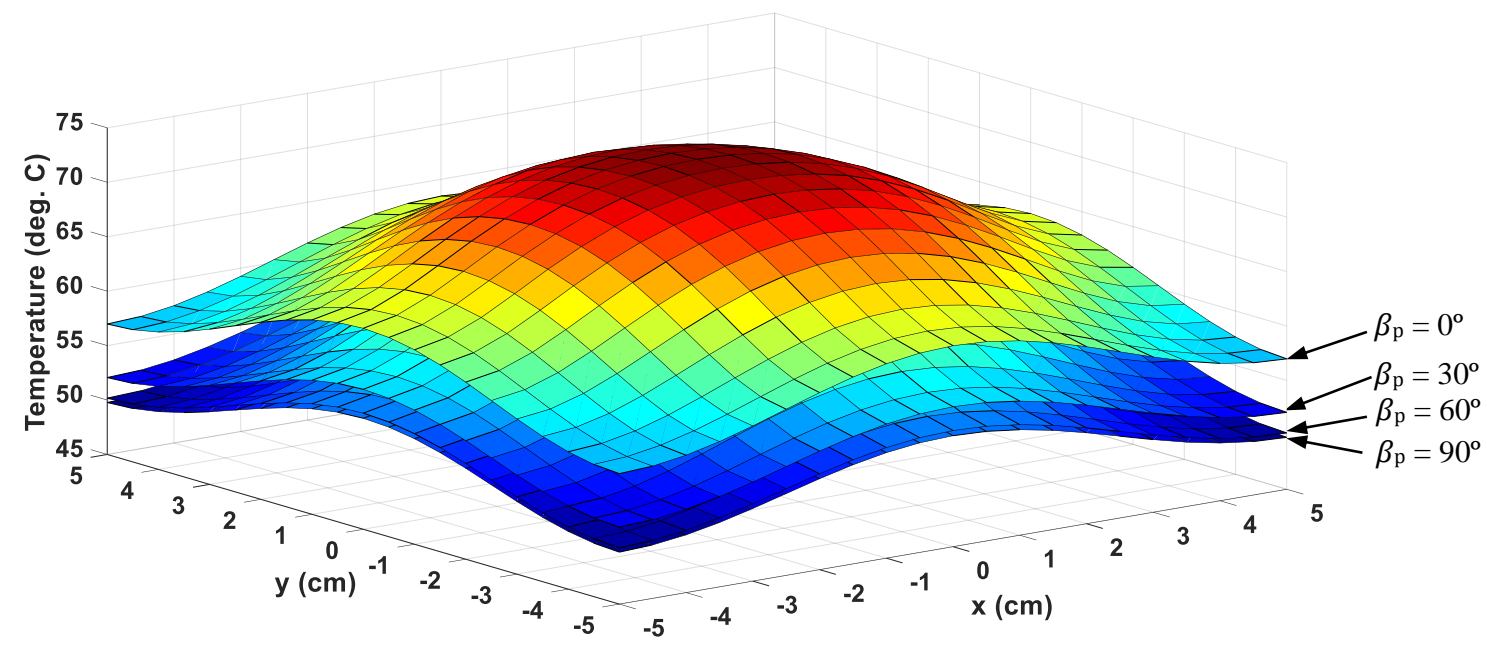

(a) Monocrystalline silicon solar cell 


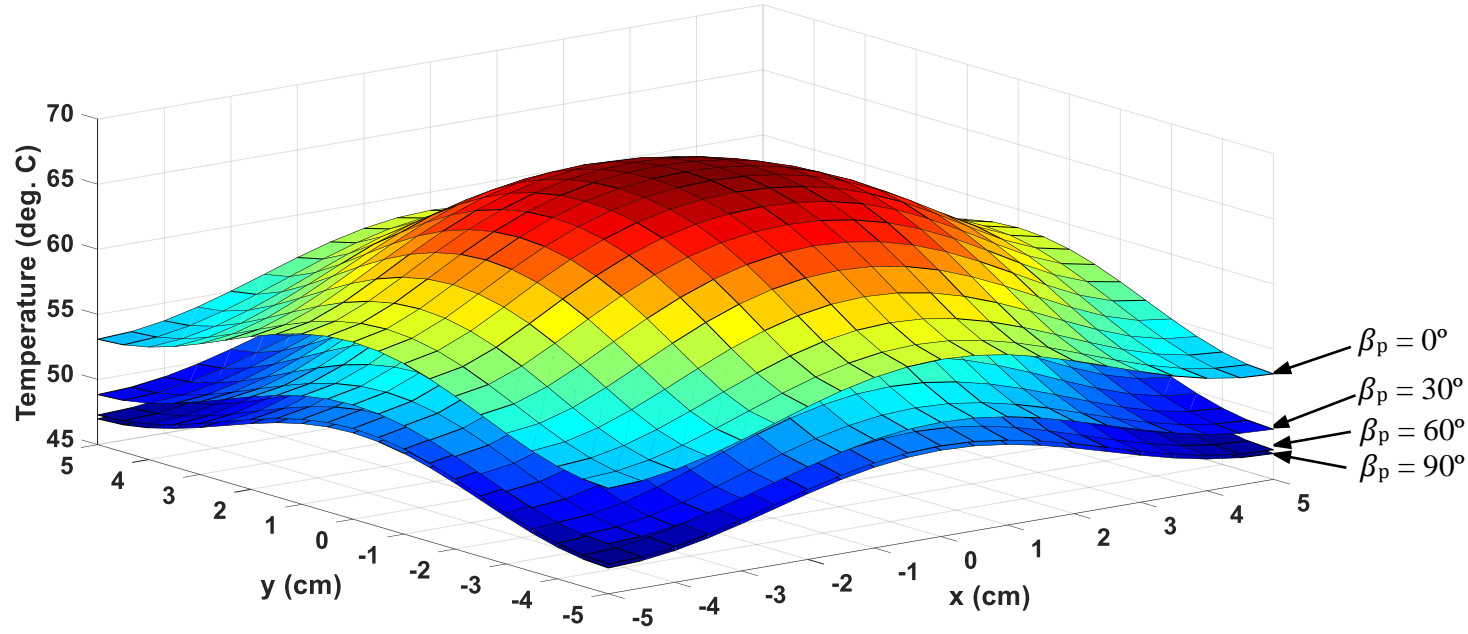

(b) Dye-sensitized solar cell

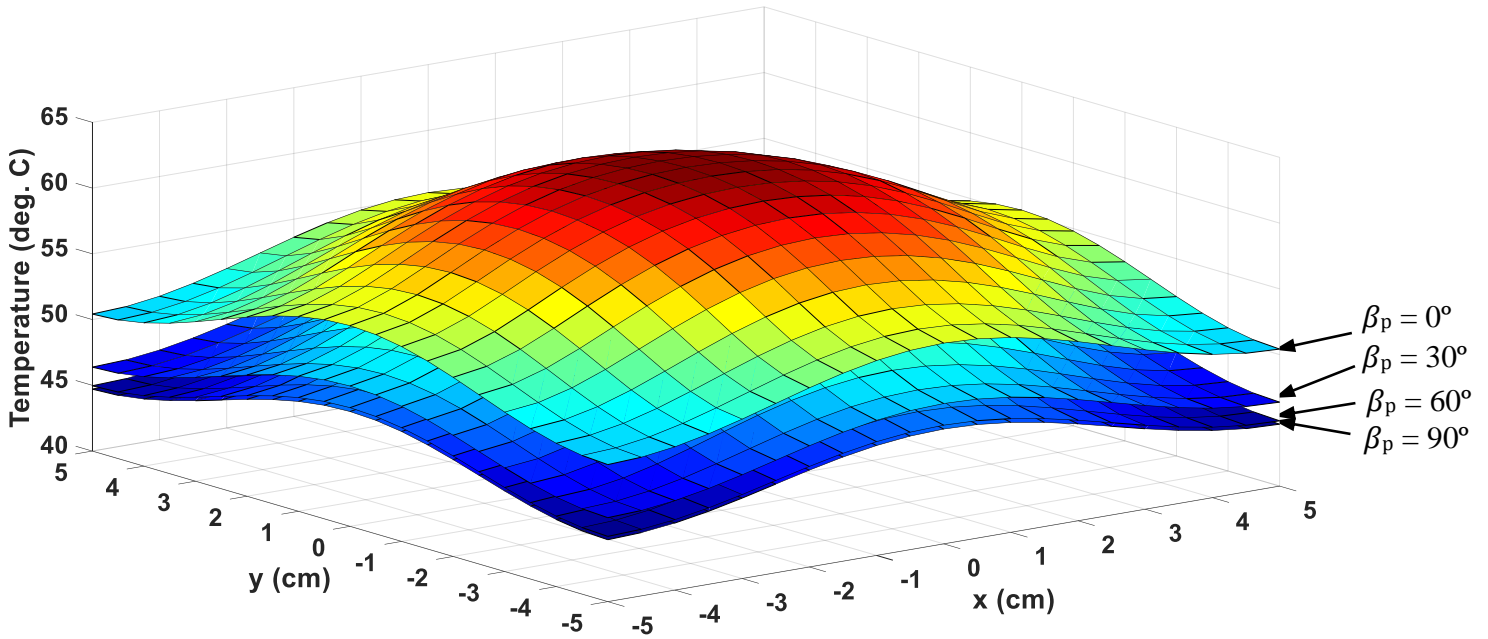

(c) Perovskite solar cell

Fig. 15 Effect of the inclination angle on the temperature distributions of the cells

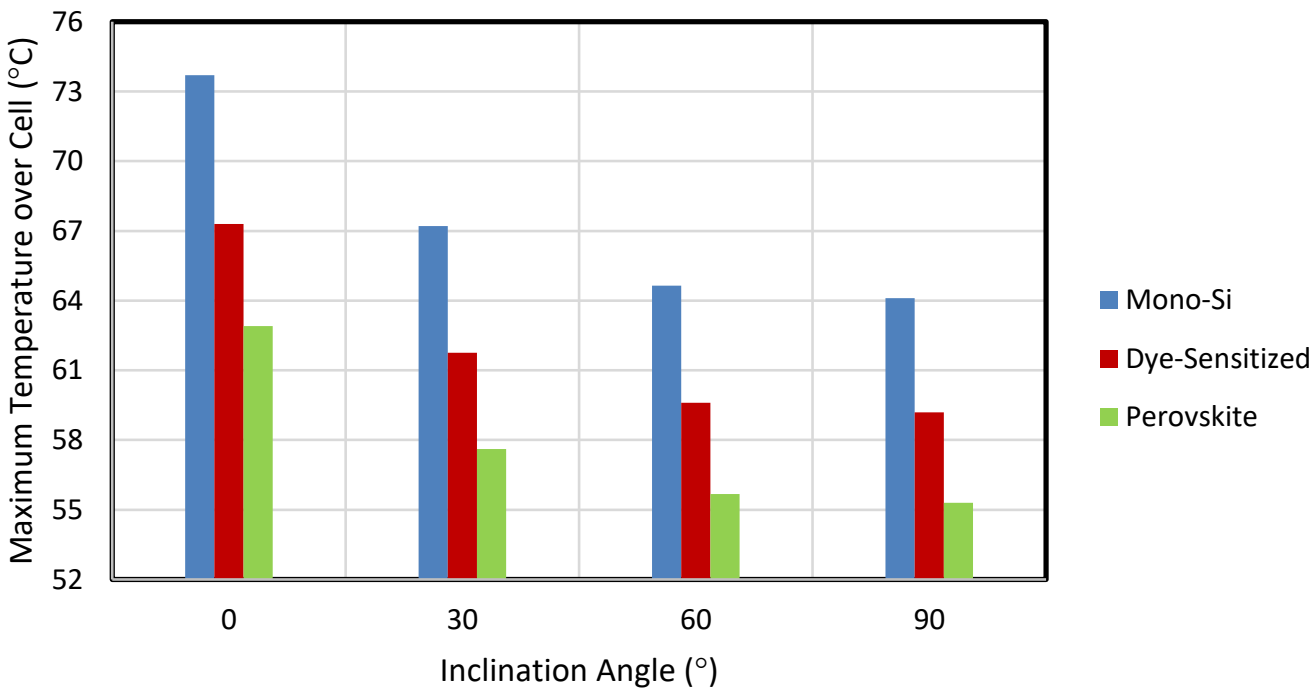




\subsection{Effect of Solar Irradiance on Cell Temperature}

427 The effect of solar irradiance on the temperature distributions is shown in Fig. 17 keeping $428 \beta_{p}=45^{\circ}, S=1000 \mathrm{~W} / \mathrm{m}^{2}$ and $\gamma_{\mathrm{w}}=0^{\circ}$. The corresponding variations in the maximum 429 temperature of the cells are plotted in Fig. 18. It can be seen that as solar irradiance 430 increases from $250 \mathrm{~W} / \mathrm{m}^{2}$ to $1000 \mathrm{~W} / \mathrm{m}^{2}$, the maximum temperature point on the surface

431 of the cell rises from 39 to $66^{\circ} \mathrm{C}$ for mono-Si, $37^{\circ} \mathrm{C}$ to $61^{\circ} \mathrm{C}$ for $\mathrm{DSSC}$ and $36^{\circ} \mathrm{C}$ to $56^{\circ} \mathrm{C}$ 432 for perovskite. Thus, the cell temperature increases with increase in solar irradiance. It is 433 due to the fact that for higher solar irradiance, the heat generation in the cell is also higher.

434 Thus, higher solar irradiance leads to larger accumulation of heat in the cell resulting in 435 higher cell temperature.

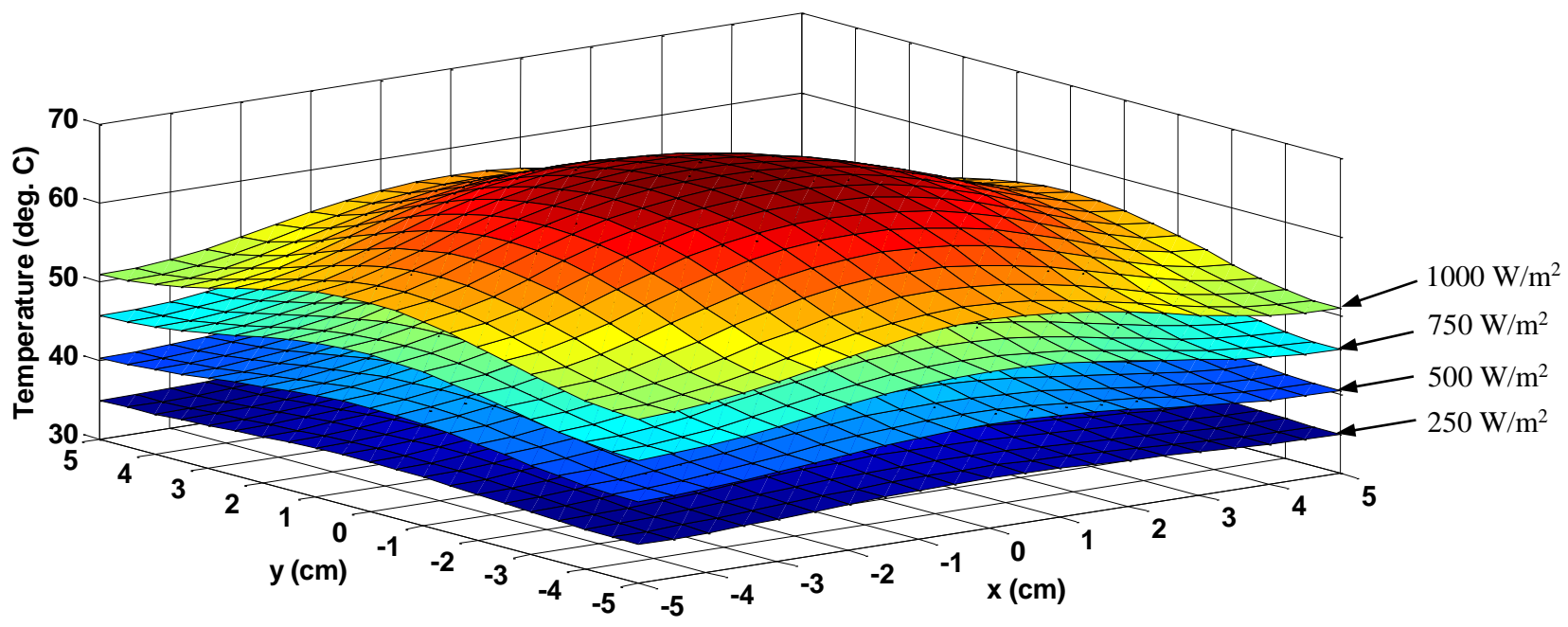




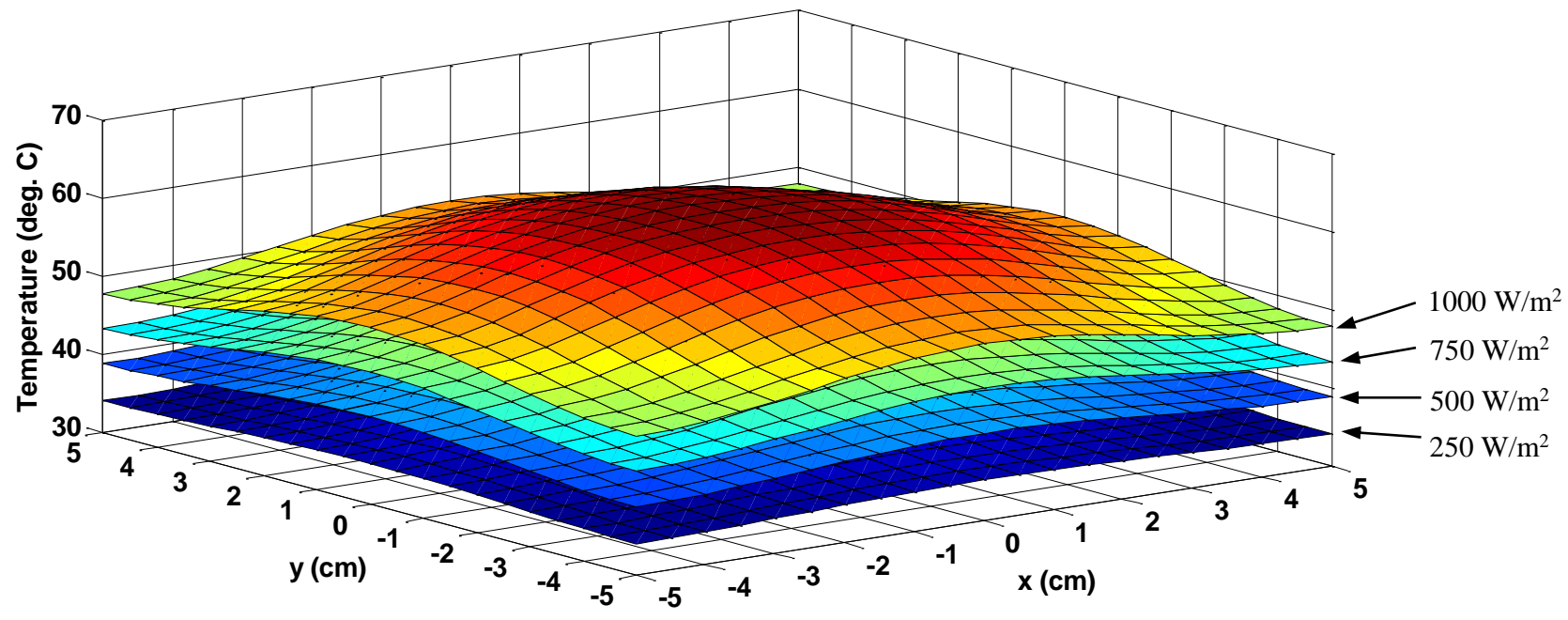

(b) Dye-sensitized solar cell

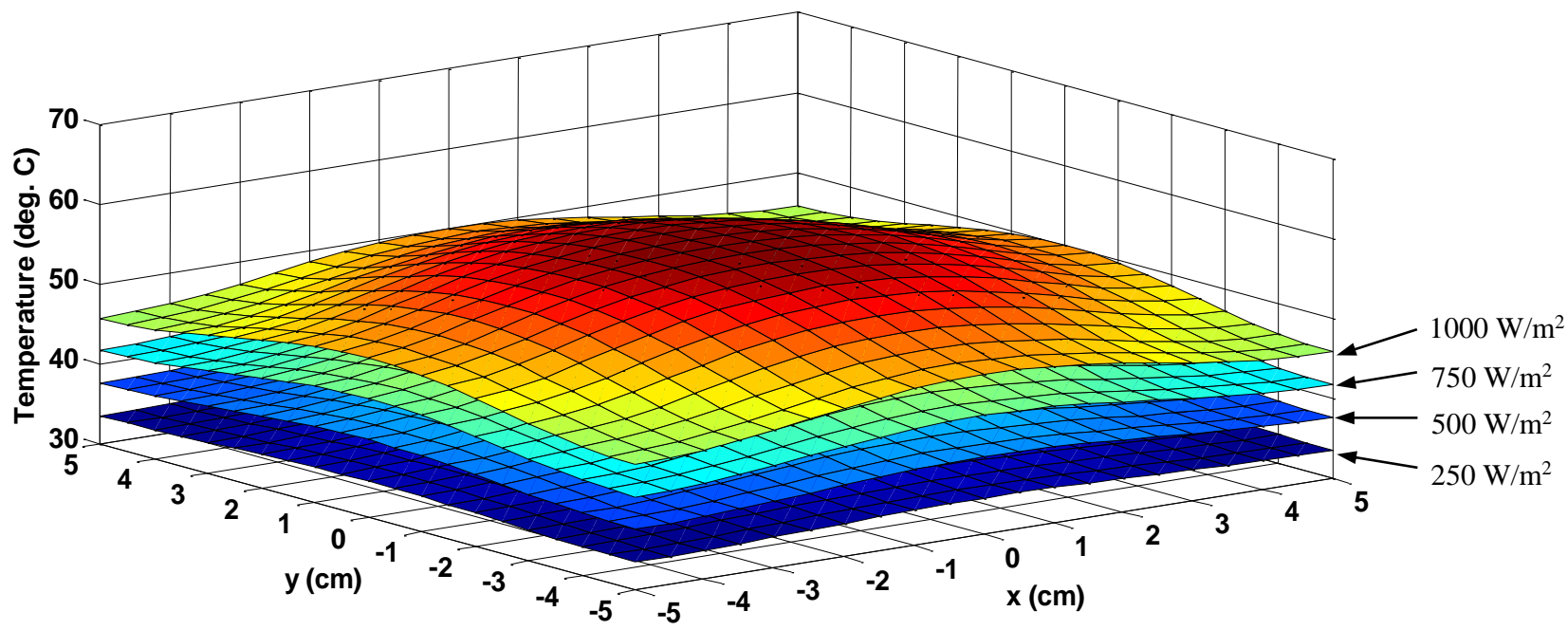

(c) Perovskite solar cell

Fig. 17 Effect of the solar irradiance on the temperature distributions of the cells

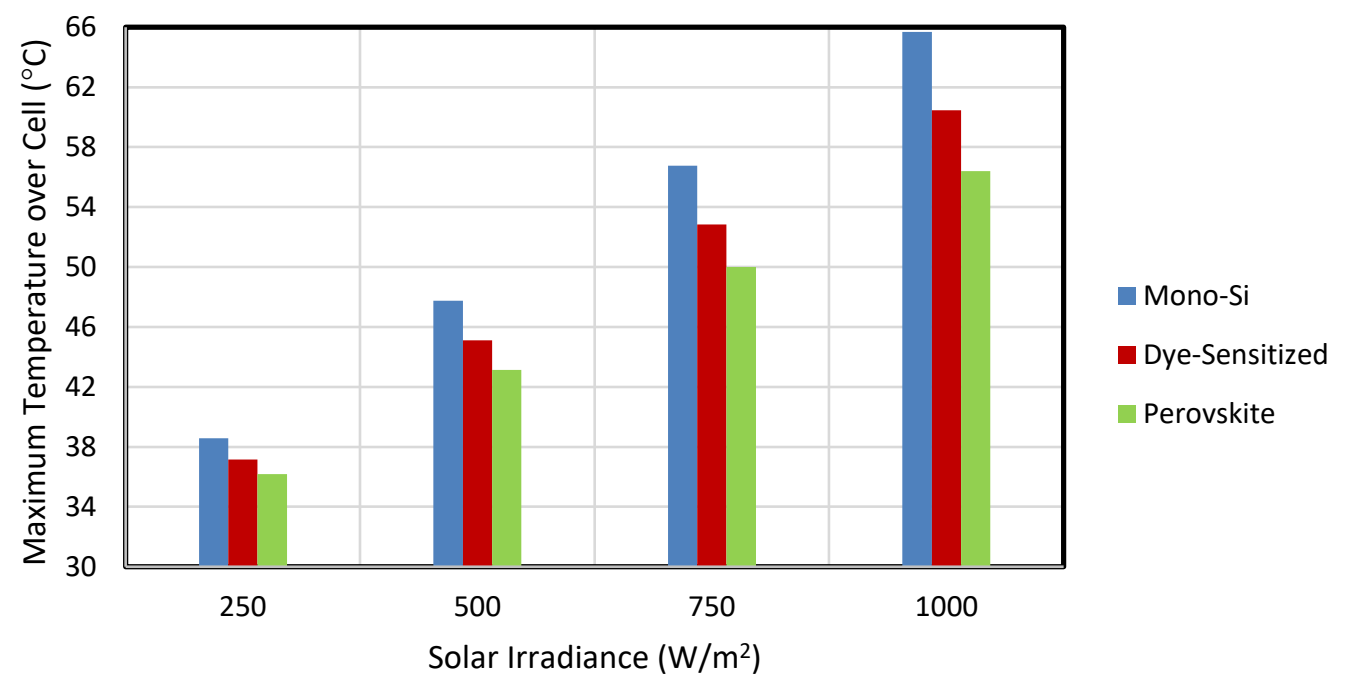

Fig. 18 Effect of solar irradiance on the maximum temperature over the cells 


\subsection{Effect of Wind Direction on Efficiency}

446 The effect of wind direction on the efficiency of the cells is shown in Fig. 19 keeping 447 other parameters fixed. It can be seen that as wind-azimuthal increases from $0^{\circ}$ to $90^{\circ}$, 448 the efficiency decreases from $22.1 \%$ to $21.3 \%$ for mono-Si, $19.0 \%$ to $18.0 \%$ for 449 perovskite and $12.0 \%$ to $11.9 \%$ for DSSC. Thus, the cell efficiency decreases with 450 increase in wind-azimuthal. It is due to the fact that when wind-azimuthal is very high, 451 the cell temperature is higher which can be seen from Fig. 12. Thus, larger wind azimuthal 452 leads to larger accumulation of heat in the cell resulting in lesser cell efficiency.

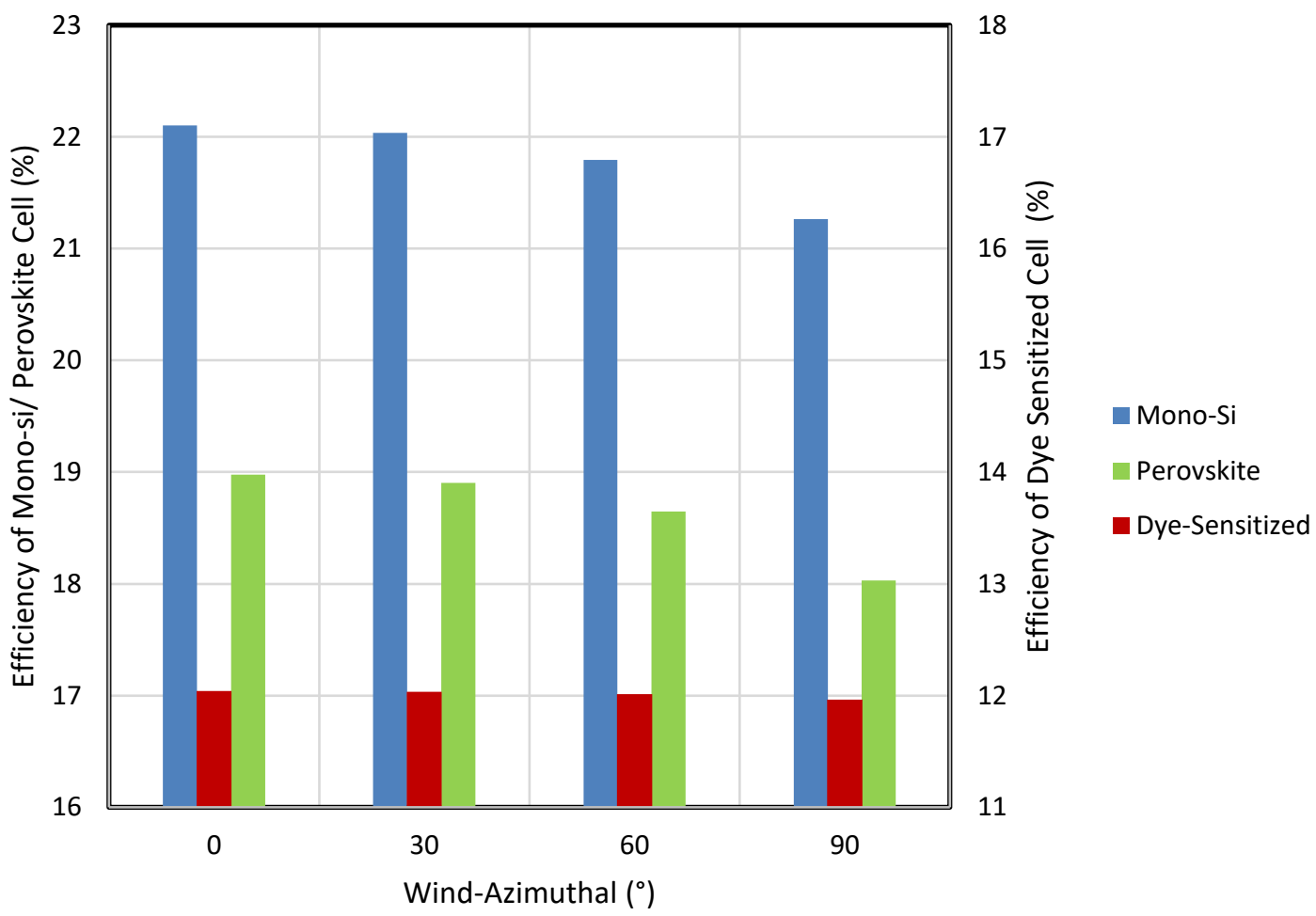




\subsection{Effect of Wind Speed on Efficiency}

456 The effect of wind speed on the efficiency of the cells is shown in Fig. 20 keeping other 457 parameters fixed. It can be seen that as wind speed decreases from $5 \mathrm{~m} / \mathrm{s}$ to $0.2 \mathrm{~m} / \mathrm{s}$, the 458 efficiency decreases from $22.2 \%$ to $20.7 \%$ for mono-Si, from $19.2 \%$ to $17.3 \%$ for 459 perovskite and from $12.1 \%$ to $11.9 \%$ for DSSC. Thus, the cell efficiency decreases with 460 decrease in wind-speed. It is due to the fact that when wind speed is high, the cell 461 temperature is lower which can be seen from Fig. 14. Thus, higher wind speed leads to 462 lesser accumulation of heat in the cell resulting in higher efficiency.

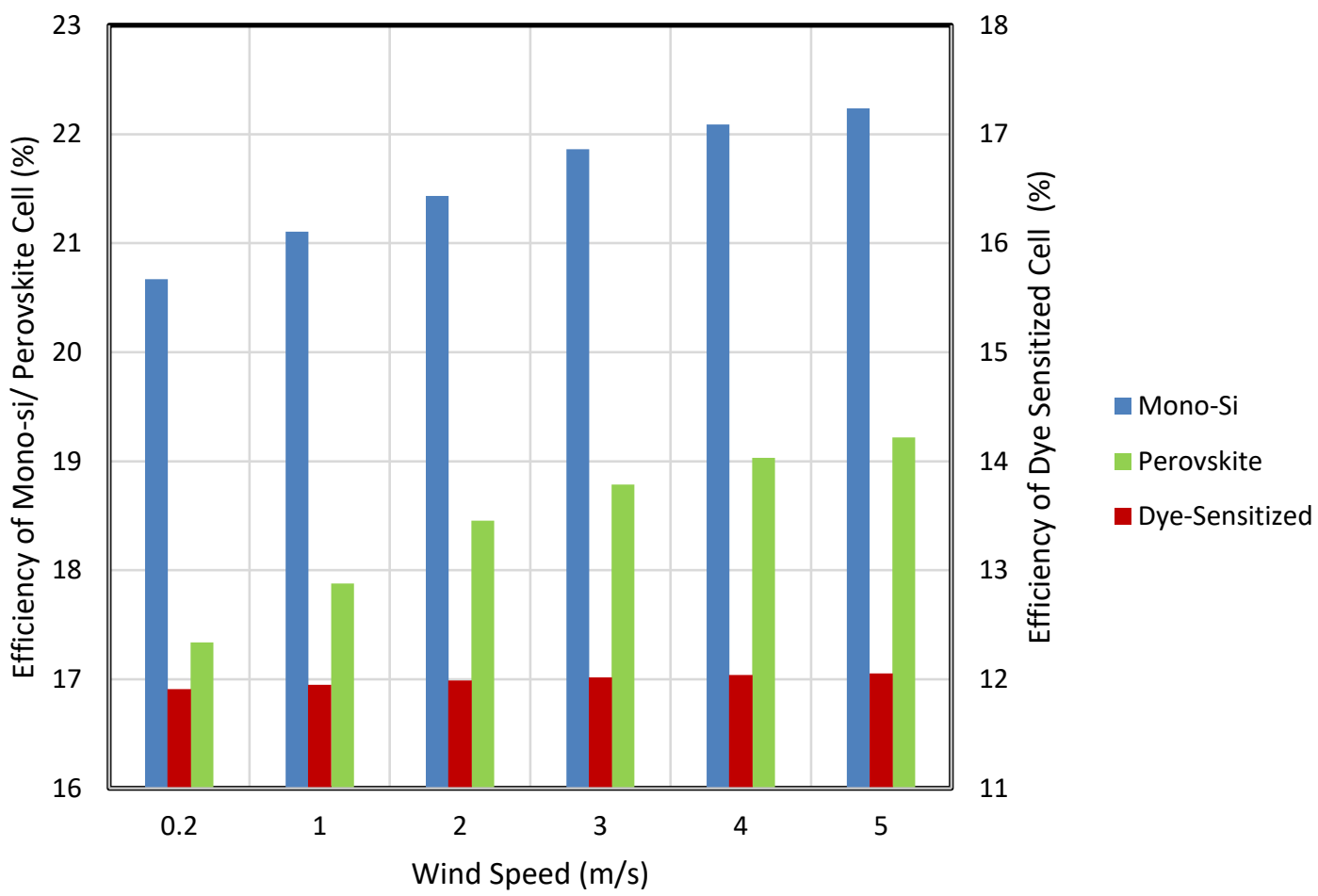

Fig. 20 Effect of wind speed on the efficiency of the cells 


\subsection{Effect of Inclination Angle on Efficiency}

466 The effect of inclination angle on the efficiency of the cells is shown in Fig. 21 keeping 467 other parameters fixed. It can be seen that as inclination angle decreases from $90^{\circ}$ to $0^{\circ}$, 468 the efficiency decreases from $22.4 \%$ to $21.3 \%$ for mono-Si, $19.1 \%$ to $18.1 \%$ for 469 perovskite and $12.1 \%$ to $12.0 \%$ for DSSC. It is due to the fact that when inclination angle 470 is very high, the cell temperature is lower which can be seen from Fig. 16. Thus, higher 471 inclination angle leads to lesser accumulation of heat in the cell resulting in higher 472 efficiency.

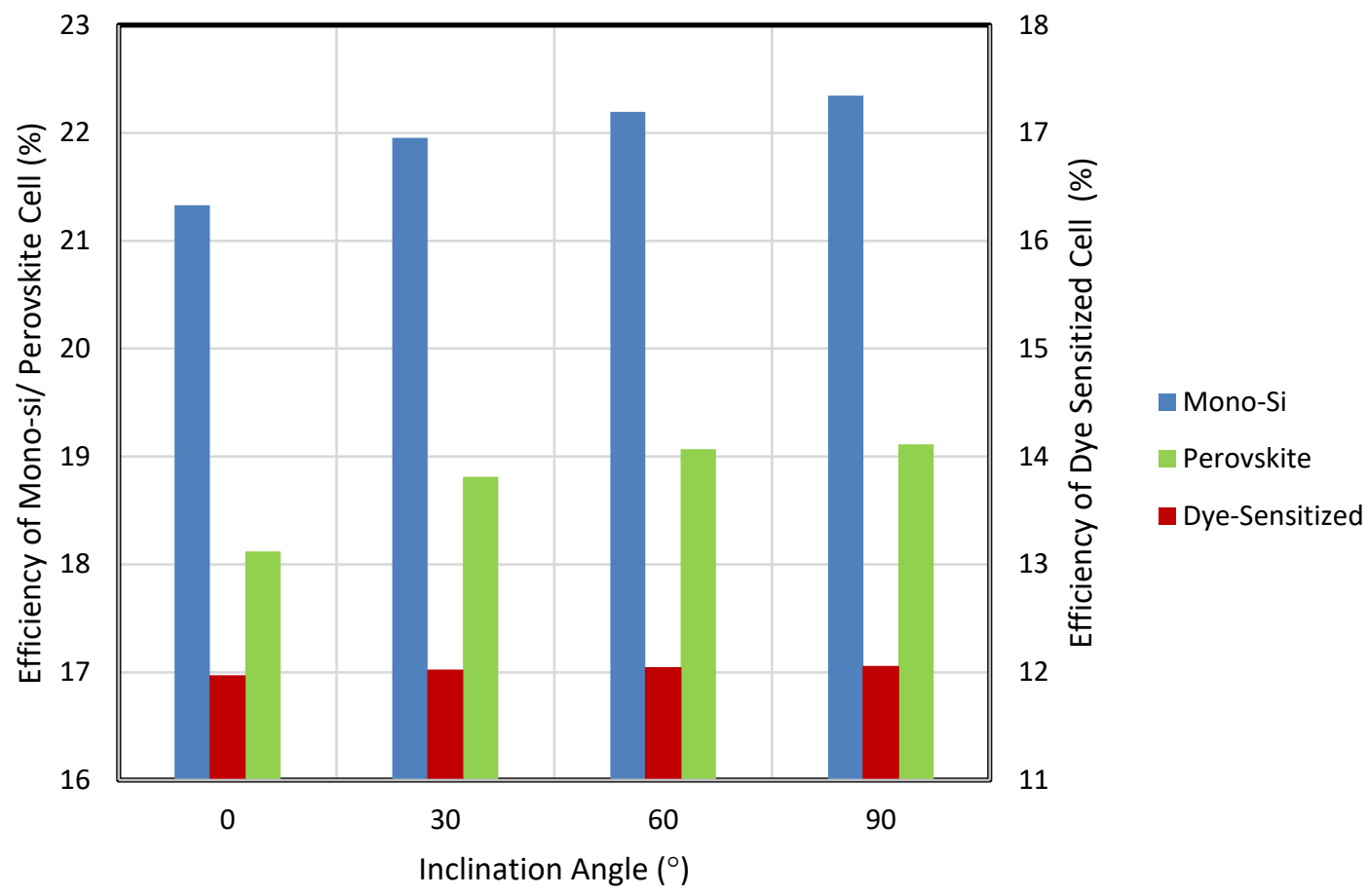




\subsection{Effect of Solar Irradiance on Efficiency}

476 The effect of solar irradiance on the efficiency of the cells is shown in Fig. 22 keeping

477 other parameters fixed. It can be seen that as solar irradiance decreases from $1000 \mathrm{~W} / \mathrm{m}^{2}$

478 to $100 \mathrm{~W} / \mathrm{m}^{2}$, the efficiency decreases from $22.1 \%$ to $20.0 \%$ for mono-Si, $19.0 \%$ to $17.5 \%$

479 for perovskite and $12.0 \%$ to $10.7 \%$ for DSSC. It is due to the fact that when solar

480 irradiance is low, the current generation by cell is lesser and the cell temperature is also

481 lower. However, the negative effect of lesser current generation on the cell efficiency

482 dominates over the positive effect of lower cell temperature. Thus, lower solar irradiance

483 leads to lesser efficiency.

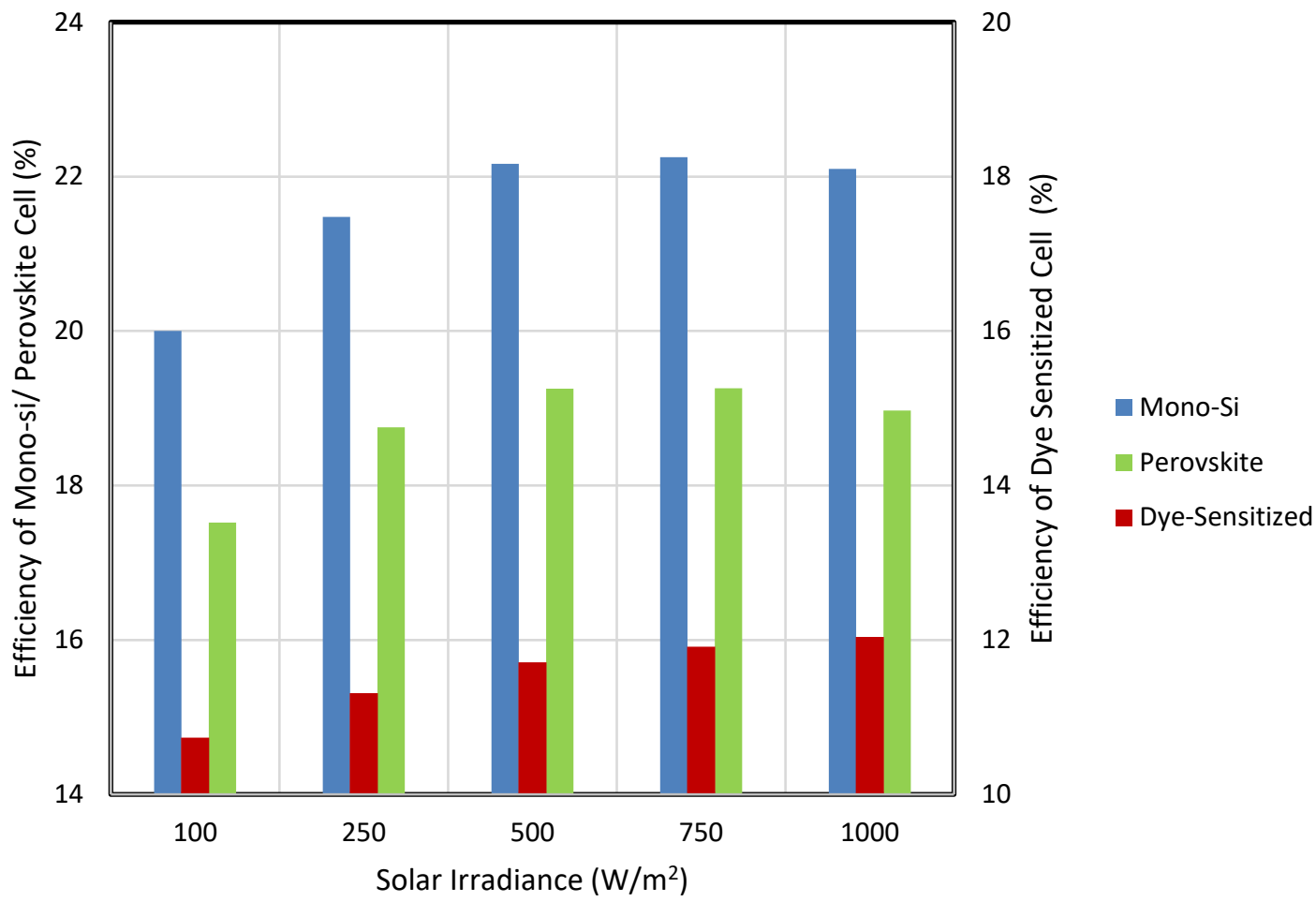

Fig. 22 Effect of solar irradiance on the efficiency of the cells 


\section{Conclusions}

487 Three dimensional analysis of DSSC, perovskite and mono-Si cells has been carried out under non-uniform 488 solar flux and an analytical expression is derived. Using the proposed analytical expression, the effects of 489 wind-azimuth angle, its speed, solar irradiance and inclination of the system on the temperature 490 distributions, heat losses and the efficiency of the cells are investigated. It is concluded that

491 (i) For perovskite, the increment in wind-azimuthal from $0^{\circ}$ to $90^{\circ}$ reduces the efficiency from 19.0 to

(ii) For mono-Si, the increment in wind-azimuthal $0^{\circ}$ to $90^{\circ}$ reduces the efficiency from 22.1 to $21.3 \%$ and increases the maximum temperature from $66^{\circ} \mathrm{C}$ to $75^{\circ} \mathrm{C}$.

(iii) For DSSC, the increment in wind-azimuthal $0^{\circ}$ to $90^{\circ}$ reduces the efficiency from 12.0 to $11.9 \%$ and increases the maximum temperature from $61^{\circ} \mathrm{C}$ to $68^{\circ} \mathrm{C}$.

(iv) For perovskite, the increment in wind speed 0.2 to $5 \mathrm{~m} / \mathrm{s}$ elevates the efficiency from $17.3 \%$ to $19.2 \%$ and reduces the maximum temperature from $67^{\circ} \mathrm{C}$ to $55^{\circ} \mathrm{C}$.

(v) For perovskite, the decrement in inclination $90^{\circ}$ to $0^{\circ}$ reduces the efficiency from $19.1 \%$ to $18.1 \%$ and increases the maximum temperature from $55^{\circ} \mathrm{C}$ to $63^{\circ} \mathrm{C}$.

(vi) For perovskite, the decrement in solar irradiance from 1000 to $100 \mathrm{~W} / \mathrm{m}^{2}$ reduces the efficiency from $19.0 \%$ to $17.5 \%$.

It is concluded that the optimum conditions for the operation of the solar cells are the wind direction from south towards north, high wind speed and high solar irradiance. 
505 Appendix A

506 A.1 Equations to evaluate the constants $A_{i}$ and $B_{i}($ for $i=1$ to 5$)$

507

$\int_{-L / 2}^{L / 2} \int_{-w / 2}^{w / 2}\left[k_{2} \frac{\partial T_{2}}{\partial z}{ }_{a t z=t_{2}}\right] d x d y+\int_{-L / 2}^{L / 2} \int_{-w / 2}^{w / 2}\left[-k_{3} \frac{\partial T_{3}}{\partial z}\right.$ at $\left.z=t_{2}\right] d x d y=\int_{-L / 2}^{L / 2} \int_{-w / 2}^{w / 2} H(x, y) d x d y$

$508 \int_{-L / 2}^{L / 2} \int_{-w / 2}^{w / 2}\left[k_{1} \frac{\partial T_{1}}{\partial z}{ }_{\text {at } z=t_{1}}\right] d x d y=\int_{-L / 2}^{L / 2} \int_{-w / 2}^{w / 2}\left[k_{2} \frac{\partial T_{2}}{\partial z}\right.$ at $\left.z=t_{1}\right] d x d y$

$509 \int_{-L / 2}^{L / 2} \int_{-w / 2}^{w / 2}\left[k_{3} \frac{\partial T_{3}}{\partial z}\right.$ at $\left.z=t_{3}\right] d x d y=\int_{-L / 2}^{L / 2} \int_{-w / 2}^{w / 2}\left[k_{4}{\frac{\partial T_{4}}{\partial z}}_{a t z=t_{3}}\right] d x d y$

510

$\int_{-L / 2}^{L / 2} \int_{-w / 2}^{w / 2}\left[k_{4} \frac{\partial T_{4}}{\partial z}{ }_{\text {at } z=t_{4}}\right] d x d y=\int_{-L / 2}^{L / 2} \int_{-w / 2}^{w / 2}\left[k_{5} \frac{\partial T_{5}}{\partial z}\right.$ at $\left.z=t_{4}\right] d x d y$

$511 \int_{-L / 2}^{L / 2} \int_{-w / 2}^{w / 2}\left[T_{1}(x, y, z)_{a t ~} z=t_{1}\right] d x d y=\int_{-L / 2}^{L / 2} \int_{-w / 2}^{w / 2}\left[T_{2}(x, y, z)_{\text {at } z=t_{1}}\right] d x d y$

$512 \int_{-L / 2} \int_{-w / 2}^{w / 2}\left[T_{2}(x, y, z)_{a t ~} z=t_{2}\right] d x d y=\int_{-L / 2}^{L / 2} \int_{-w / 2}^{w / 2}\left[T_{3}(x, y, z)_{a t z=t_{2}}\right] d x d y$

513

$\begin{array}{llll}L / 2 & w / 2 & L / 2 & w / 2\end{array}$

$\int_{-L / 2} \int_{-w / 2}\left[T_{3}(x, y, z)_{a t z=t_{3}}\right] d x d y=\int_{-L / 2} \int_{-w / 2}\left[T_{4}(x, y, z)\right.$ at $\left.z=t_{3}\right] d x d y$

$514 \int_{-L / 2}^{L / 2} \int_{-w / 2}^{w / 2}\left[T_{4}(x, y, z)_{a t ~} z=t_{3}\right] d x d y=\int_{-L / 2}^{L / 2} \int_{-w / 2}^{w / 2}\left[T_{5}(x, y, z)_{\text {at } z=t_{4}}\right] d x d y$

515

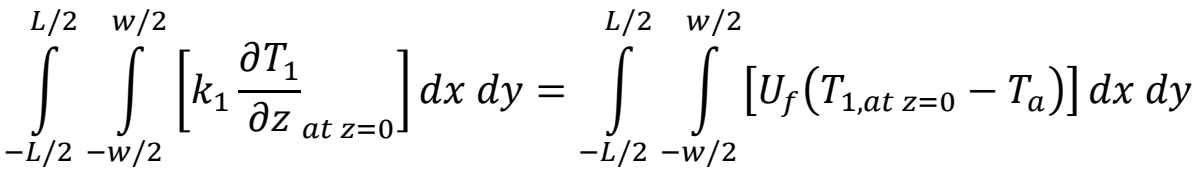

$516 \int_{-L / 2}^{L / 2} \int_{-w / 2}^{w / 2}\left[-k_{5} \frac{\partial T_{5}}{\partial z}\right.$ at $\left.z=t_{5}\right] d x d y=\int_{-L / 2}^{L / 2} \int_{-w / 2}^{w / 2}\left[U_{r}\left(T_{5, \text { at } z=t_{5}}-T_{a}\right)\right] d x d y$ 
518 B.1 Equations to evaluate the constants $C_{m, i}$ and $D_{m, i}($ for $i=1$ to 5$)$

$519 \int_{-L / 2}^{L / 2} \int_{-w / 2}^{w / 2}\left[k_{2} \frac{\partial T_{2}}{\partial z}{ }_{a t z=t_{2}}-k_{3} \frac{\partial T_{3}}{\partial z}\right.$ at $\left.z=t_{2}\right] \cos \frac{2 m \pi x}{L} d x d y=\int_{-L / 2}^{L / 2} \int_{-w / 2}^{w / 2} H(x, y) \cos \frac{2 m \pi x}{L} d x d y$

$520 \int_{-L / 2}^{L / 2} \int_{-w / 2}^{w / 2}\left[k_{1} \frac{\partial T_{1}}{\partial z}{ }_{a t z=t_{1}}\right] \cos \frac{2 m \pi x}{L} d x d y=\int_{-L / 2}^{L / 2} \int_{-w / 2}^{w / 2}\left[k_{2} \frac{\partial T_{2}}{\partial z}{ }_{a t z=t_{1}}\right] \cos \frac{2 m \pi x}{L} d x d y$

$521 \int_{-L / 2}^{L / 2} \int_{-w / 2}^{w / 2}\left[k_{3} \frac{\partial T_{3}}{\partial z}{ }_{a t z=t_{3}}\right] \cos \frac{2 m \pi x}{L} d x d y=\int_{-L / 2}^{L / 2} \int_{-w / 2}^{w / 2}\left[k_{4} \frac{\partial T_{4}}{\partial z}\right.$ at $\left.z=t_{3}\right] \cos \frac{2 m \pi x}{L} d x d y$

$522 \int_{-L / 2}^{L / 2} \int_{-w / 2}^{w / 2}\left[k_{4} \frac{\partial T_{4}}{\partial z}{ }_{a t z=t_{4}}\right] \cos \frac{2 m \pi x}{L} d x d y=\int_{-L / 2}^{L / 2} \int_{-w / 2}^{w / 2}\left[k_{5} \frac{\partial T_{5}}{\partial z}\right.$ at $\left.z=t_{4}\right] \cos \frac{2 m \pi x}{L} d x d y$

$523 \quad \int_{-L / 2}^{L / 2} \int_{-w / 2}^{w / 2}\left[T_{1}(x, y, z)_{a t} z=t_{1}\right] \cos \frac{2 m \pi x}{L} d x d y=\int_{-L / 2}^{L / 2} \int_{-w / 2}^{w / 2}\left[T_{2}(x, y, z)_{a t} z=t_{1}\right] \cos \frac{2 m \pi x}{L} d x d y$

$524 \int_{-L / 2}^{L / 2} \int_{-w / 2}^{w / 2}\left[T_{2}(x, y, z)_{a t z=t_{2}}\right] \cos \frac{2 m \pi x}{L} d x d y=\int_{-L / 2}^{L / 2} \int_{-w / 2}^{w / 2}\left[T_{3}(x, y, z)_{a t z=t_{2}}\right] \cos \frac{2 m \pi x}{L} d x d y$

$525 \int_{-L / 2}^{L / 2} \int_{-w / 2}^{w / 2}\left[T_{3}(x, y, z)_{a t z=t_{3}}\right] \cos \frac{2 m \pi x}{L} d x d y=\int_{-L / 2}^{L / 2} \int_{-w / 2}^{w / 2}\left[T_{4}(x, y, z)_{a t} z=t_{3}\right] \cos \frac{2 m \pi x}{L} d x d y$

526

$\int_{-L / 2}^{L / 2} \int_{-w / 2}^{w / 2}\left[T_{4}(x, y, z)_{a t z=t_{4}}\right] \cos \frac{2 m \pi x}{L} d x d y=\int_{-L / 2}^{L / 2} \int_{-w / 2}^{w / 2}\left[T_{5}(x, y, z)_{a t z=t_{4}}\right] \cos \frac{2 m \pi x}{L} d x d y$

527

$\int_{-L / 2}^{L / 2} \int_{-w / 2}^{w / 2}\left[k_{1} \frac{\partial T_{1}}{\partial z}\right.$ at $\left.z=0\right] \cos \frac{2 m \pi x}{L} d x d y=\int_{-L / 2}^{L / 2} \int_{-w / 2}^{w / 2}\left[U_{f}\left(T_{1, a t z=0}-T_{a}\right)\right] \cos \frac{2 m \pi x}{L} d x d y$

$528 \int_{-L / 2}^{L / 2} \int_{-w / 2}^{w / 2}\left[-k_{5} \frac{\partial T_{5}}{\partial z}\right.$ at $\left.z=t_{5}\right] \cos \frac{2 m \pi x}{L} d x d y=\int_{-L / 2}^{L / 2} \int_{-w / 2}^{w / 2}\left[U_{r}\left(T_{5, a t z=t_{5}}-T_{a}\right)\right] \cos \frac{2 m \pi x}{L} d x d y$ 


\section{References}

533 [1] Zhang X., Li M., Ge Y., Li G. Techno-economic feasibility analysis of solar photovoltaic power generation for buildings. Applied Thermal Engineering 108 (2016) 1362-1371.

[2] Tabasi S., Yousefi H., Noorollahi Y., Aramesh M. A detailed investigation and performance optimization of a photovoltaic panel integrated with a reflecting mirror. Applied Thermal Engineering 160 (2019) 114074.

[3] Bayrak F., Oztop H. F. Effects of static and dynamic shading on thermodynamic and electrical performance for photovoltaic panels. Applied Thermal Engineering 169 (2020) 114900.

[4] Goossens D., Goverde H., Catthoor F. Effect of wind on temperature patterns, electrical

[5] Senturk A. Investigation of datasheet provided temperature coefficients of photovoltaic modules under various sky profiles at the field by applying a new validation procedure. Renewable Energy $152(2020) 644-652$.

[6] Gu W., Ma T., Li M., Shen L., Zhang Y. A coupled optical-electrical-thermal model of the bifacial photovoltaic module. Applied Energy 258 (2020) 114075.

[7] Ceylan I., Yilmaz S., Inanç O., Ergün A., Gürel A. E., Acar B., Aksu A. I.. Determination of the heat transfer coefficient of PV panels. Energy 175 (2019) 978-985.

[8] Vasel A., Iakovidis F. The effect of wind direction on the performance of solar PV plants. Energy Conversion and Management 153 (2017) 455-461. 
[9] Abiola-Ogedengbe A., Hangan H., Siddiqui K. Experimental investigation of wind effects on a standalone photovoltaic (PV) module. Renewable Energy 78 (2015) 657-665.

[10] Gu W., Ma T., Shen L., Li M., Zhang Y., Zhang W. Coupled electrical-thermal modelling of photovoltaic modules under dynamic conditions. Energy 188 (2019) 116043.

[11] Ishii T., Otani K., Takashima T., Kawai S. Estimation of the maximum power temperature coefficients of PV modules at different time scales. Solar Energy Materials \& Solar Cells 95 (2011) $386-389$.

[12] Wang H., Cheng X., Yang H., He W., Chen Z., Xu L., Song D. Potential-induced degradation: Recombination behavior, temperature coefficients and mismatch losses in crystalline silicon photovoltaic power plant. Solar Energy 188 (2019) 258-264.

[13] Zhang H., Qiao X., Shen Y., Wang M. Journal of Energy Chemistry 24 (2015) 729-735.

[14] Cojocaru L., Uchida S., Sanehira Y., Gonzalez-Pedro V., Bisquert J., Nakazaki J., Kubo T., Segawa H. Chemistry Letters 44 (2015) 1557-1559.

[15] Zandi S., Saxena P., Gorji N. E., Numerical simulation of heat distribution in RGO-contacted perovskite solar cells using COMSOL. Solar Energy 197 (2020) 105-110.

[16] Saxena P., Gorji N. E., COMSOL Simulation of Heat Distribution in Perovskite Solar Cells: Coupled Optical-Electrical-Thermal 3-D Analysis. IEEE Journal of Photovoltaics 9 (2019) 16931698.

[17] Grätzel M. Dye-sensitized solar cells. Journal of Photochemistry and Photobiology C: Photochemistry Reviews 4 (2003) 145-153.

[18] Raga S. R., Santiago F.F. Physical Chemistry Chemical Physics 15 (2013) 2328-2336.

[19] Tripathi B., Yadav P., Kumar M. International Journal of Photoenergy (2013) 646407. 
[20] Sebastian P.J., Olea A., Campos J., Toledo J.A., Gamboa S.A. Solar Energy Materials \& Solar Cells 81 (2004) 349-361.

[21] Pettersson H., Gruszecki T., Johansson L., Johander P. Solar Energy Materials \& Solar Cells 77 (2003) 405-413.

[22] Chowdhury M.G., Goossens D., Goverde H., Catthoor F. Experimentally validated CFD simulations predicting wind effects on photovoltaic modules mounted on inclined surfaces. Sustainable Energy Technologies and Assessments 30 (2018) 201-208.

[23] Zhang G., Wei J., Wang Z., Xie H., Xi Y., Khalid M. Investigation into effects of non-uniform irradiance and photovoltaic temperature on performances of photovoltaic/thermal systems coupled with truncated compound parabolic concentrators. Applied Energy 250 (2019) 245-256.

[24] Yu Q., Hu,M., Li J., Wang Y., Pei G. Development of a 2D temperature-irradiance coupling model for performance characterizations of the flat-plate photovoltaic/thermal (PV/T) collector. Renewable Energy (2020) https://doi.org/10.1016/j.renene.2020.01.143

[25] Ju X., Pan X., Zhang Z., Xu C., Wei G. Thermal and electrical performance of the dense-array concentrating photovoltaic (DA-CPV) system under non-uniform illumination. Applied Energy 250 (2019) 904-915.

[26] Zhou J., Zhang Z., Liu H., Yi Q. Temperature distribution and back sheet role of polycrystalline silicon photovoltaic modules. Applied Thermal Engineering 111 (2017) 1296-1303.

[27] Amanlou Y., Hashjin T.T., Ghobadian B., Najafi G. Air cooling low concentrated photovoltaic/thermal (LCPV/T) solar collector to approach uniform temperature distribution on the PV plate. Applied Thermal Engineering 141 (2018) 413-421. 
[28] Gallero F.J.G., Maestre I.R., Hemida H., Gómez P.A. Practical approaches to assess thermal performance of a finned heat sink prototype for low concentration photovoltaics (LCPV) systems: Analytical correlations vs CFD modelling. Applied Thermal Engineering 156 (2019) 220-229.

[29] Pang W., Zhang Q., Wilson G.J., Yang Q., Yan H. Empirical influence of various environmental conditions and mass flow rates on hybrid photovoltaic thermal modules. Applied Thermal Engineering 171 (2020) 114965.

[30] Nouira M., Sammouda H. Numerical study of an inclined photovoltaic system coupled with phase change material under various operating conditions. Applied Thermal Engineering 141 (2018) 958975.

[31] Khanna S., Reddy K.S., Mallick T.K. Effect of climate on electrical performance of finned phase change material integrated solar photovoltaic. Solar Energy 174 (2018) 593-605.

[32] Khanna S., Newar S., Sharma V., Reddy K.S., Mallick T.K., Radulovic J., Khusainov R., Hutchinson D., Becerra V. Electrical enhancement period of solar photovoltaic using phase change material. Journal of Cleaner Production 221 (2019) 878-884.

[33] Singh P., Khanna S., Becerra V., Newar S., Sharma V., Mallick T.K., Hutchinson D., Radulovic J., Khusainov R. Power improvement of finned solar photovoltaic phase change material system. Energy 193 (2020) 116735.

[34] Khanna S., Sharma V., Singh S., Kedare S.B. Explicit expression for temperature distribution of receiver of parabolic trough concentrator considering bimetallic absorber tube. Applied Thermal Engineering 103 (2016) 323-332.

[35] Bonacina C., Comini G., 1973. On the solution of the nonlinear heat conduction equations by numerical methods. International Journal of Heat and Mass Transfer 16, 581-589.

[36] Armstrong S., Hurley W.G. Applied Thermal Engineering 30 (2010) 1488-1495. 